\title{
1 Transition metal-doped cryogels as bioactive materials \\ 2 for wound healing applications
}

3 Duong Luonga , Abdulla A. Yergeshov ${ }^{a}$, Mohamed Zoughaib ${ }^{a}$, Farida R. Sadykova ${ }^{a}$,

4 Bulat I. Gareev ${ }^{\mathrm{a}}$, Irina N. Savina ${ }^{\mathrm{b}}$, Timur I. Abdullin ${ }^{\mathrm{a}, *}$

5

$6 \quad{ }^{a}$ Kazan (Volga Region) Federal University, 420008 Kazan, 18 Kremlyovskaya St., Russia

$7 \quad{ }^{b}$ School of Pharmacy and Biomolecular Sciences, University of Brighton, Brighton BN2 4GJ,UK

8

$9 *$ Corresponding author. Email address: tabdulli@gmail.com, timur.abdullin@kpfu.ru (T.I. Abdullin)

ABSTRACT

Transition metals (TM) are essential microelements with various biological functions demanded in tissue regeneration applications. Little is known about therapeutic potential of TM within soft hydrogel biomaterials. The soluble TM, such as $\mathrm{Zn}, \mathrm{Cu}, \mathrm{Mn}$ and $\mathrm{Co}$, were stably incorporated into gelatin network during cryogelation. TM content in the resultant cryogels varied from $0.1 \times 10^{3}$ to $11.8 \times 10^{3} \mathrm{ppm}$, depending on the initial TM type and concentration in reaction solution. Zn was uniformly complexed with the gelatin scaffold according to elemental imaging, increasing the swelling of polymer walls and the $G^{\prime} / G^{\prime \prime}$ values and also decreasing the size of cryogel macro-pores Zn-doped cryogels supported migration of human skin fibroblasts (HSF); only upper Zn content of $11.8 \times 10^{3} \mathrm{ppm}$ in the scaffold caused c.a. 50\% inhibition of cell growth. Zn ions solubilized in culture medium were more active towards HSF ( $\mathrm{IC}_{50} \approx 0.3 \mathrm{mM}$ ). Treatment of splinted full-skin excisional wounds in rats with the Zn-doped and non-doped cryogels showed that Zn considerably promotes d passing inflammatory/proliferation phases of healing process, inducing more intense dermis formation and structuration. The results show the feasibility of development of cryogel based formulations with different TM and support high phase-specific ability of the Zn-gelatin cryogels to repair acute wounds.

Keywords: Transition metals; Biomaterials; Cryogels; Gelatin; Zinc; Excisional wound model; Wound healing

\section{Introduction}


1 Dealing with traumatic injuries of soft and solid body tissues is one of the leading 2 worldwide problems, which features high costs of medical treatment and increased risk for 3 life. Repairing sever injuries, e.g. extensive burns or peripheral nerve gaps, often requires the 4 use of donor or artificial grafts to compensate post-traumatic loss of tissues and increase efficacy of tissue regeneration and function recovery [1, 2].

Autologous and decellularized allo-/xenogenic tissues with native histochemical organization are considered the most potent grafts for clinical applications. However, their obvious disadvantages, such as low availability and reproducibility, risk of necrosis/rejection, size misfit, prompt the development of artificial tissue analogs [[1],[2],[3]]. Many attempts have been made to impart specific regenerative activity to biocompatible/biodegradable materials. To increase ability of the biomaterials to repair damaged tissues, extracellular matrix (ECM) proteins and/or polysaccharides with natural bioactive motifs are often used,[4]. Additionally, the biomaterials are produced in the form of soft/self-assembled constructs [5], nanofibers [6] or porous scaffolds [7] to support mass transport of nutrients and infiltration of cells.

Additional modifications of the biomaterials with bioactive components are often required to boost their therapeutic efficacy. These modifications particularly include combination of matrices with multipotent stromal cells as a source of secreted regenerative factors [[8],[9],[10]], introduction of biomacromolecules, e.g. recombinant growth factors/cytokines or plasmid DNA $[9,11]$, as well as introduction of bioactive peptide motifs [12]. These approaches eventually enable own cellular mechanisms of tissue regeneration and in situ vascularization, providing therapeutic benefits upon different types of trauma.

Transition metals (TM), such as iron, zinc, copper, cobalt, manganese, in the form of soluble compounds and particles are less explored components of tissue-engineered materials. TM ions play various vital functions in living organisms [13], apart from widely exploited antibacterial activity $[14,15]$, and represent a considerable interest for tissue regeneration purposes [16]. TM are acting as a cofactor of different essential enzymes including oxidoreductases [13]. They also participate in non-enzymatic generation of reactive oxygen species (ROS), e.g. through Fenton-type/Haber-Weiss reactions [17, 18], and thereby regulate key redox-sensitive transcriptional factors and signaling pathways involved in regeneration [19, 20].

In particular, cobalt (II) ions $\left(\mathrm{Co}^{2+}\right)$ were shown to cause hypoxia-like state in cells via increasing expression of hypoxia-inducible factor (HIF)-1 $\alpha$ and vascular endothelial growth factor (VEGF), resulting in pro-angiogenic effects [[21],[16],[22]]. Manganese and copper 
1 are the cofactors of a broad number of enzymes including superoxide dismutases converting

2 superoxide radical into hydrogen peroxide. As a cofactor of lysyl oxidase $\mathrm{Cu}^{2+}$ is also required for the enzyme-mediated stabilization of collagen and elastin fibers in connective

4 tissues $[13,16]$. Copper, along with cobalt, stimulates angiogenesis in vitro and in vivo

5 [[16],[23],[24]]; the activity is modulated by complex formation between $\mathrm{Cu}^{2+}$ and

6 oligopeptides such as Gly-His-Lys [25].

7 healing of damaged, inflamed and degenerated tissues (see reviews [26, 27] and references within). Since the development of $\mathrm{ZnO}$-containing dressing (Unna boot), $\mathrm{Zn}^{2+}$ based topical formulations have been widely used for management of acute and chronic wounds [27]. Wound healing activity of $\mathrm{Zn}^{2+}$ is associated with a number of zinc-dependent proteins and enzymes, which are responsible for transcriptional regulation, DNA repair, metabolic processing including ECM turnover [26, 27]. In addition, it is associated with antioxidant effects of $\mathrm{Zn}^{2+}$ due to interference with Fenton-type reactions, protection of proteins sulfhydryl groups and induction of metallothionein biosynthesis [28]. Systemic and local immunomodulatory properties of $\mathrm{Zn}^{2+}$, reviewed in [28], may also contribute to its wound healing activity [26].

The examples of TM-containing tissue-engineered materials and their biological applications are overviewed in [16]. Most of them are designed as solid bone-replacing materials doped with TM to enhance their osteogenic/angiogenic potential [[16],[29],[30],[31]]. Specifically, zinc-reinforced calcium silicate ceramics were produced and studied as a substrate for human osteoblast-like cells and osteoclasts. The TM dopant was found to increase cell proliferation and differentiation including expression of osteoclastspecific markers, e.g. alkaline phosphatase, collagen type I, osteocalcin, receptor activator of $\mathrm{NF}_{\mathrm{K}} \mathrm{B}$ ligand, osteoprotegerin [32]. $\mathrm{Co}^{2+}$ incorporation into mesoporous bioactive glass scaffold was shown to substantially promote expression of VEGF, HIF-1 $\alpha$ and bone-related factors in human bone marrow stromal cells [21]. $\mathrm{Co}^{2+}$-containing resorbable bioactive glass particles were embedded into porous collagen/glycosaminoglycan sponge. The composite scaffold enhanced VEGF expression and tubule formation by endothelial cells as well as proliferation and osteogenic differentiation of MC3T3-E1 cells [22]. Similarly, $\mathrm{Cu}^{2+}$ modified macroporous glass material with mesoporous channels, which combined angiogenic, osteostimulating and antibacterial properties, was developed as a candidate for bone tissue repair [24]. 
1 There is lack of reports on therapeutic applications of TM-containing hydrogel materials.

2 The fluctuation of the local TM content in hydrogels could compromise their therapeutic

3 efficacy and even have side effects associated with cytotoxic and carcinogenic properties of

4 the TM compounds [33]. To address the problem, a cryogel based formulation carrying pure

5 bioactive TM was developed in this study. The macroporous structure of cryogels supports enhanced diffusion of water/solutes and cellular migration within the bulk of the material in

7

8 great contrast to non-porous hydrogels [34, 35]. Hence, increased availability and uniform local concentrations of entrapped bioactive components in whole cryogels could be achieved. In this study, the cryogels composed of gelatin and doped with TM were developed and characterized as a promising candidate for therapeutic applications. In particular, Zn-gelatin cryogels exhibited dopant-controllable physicochemical properties and provided effective phase-specific simulation of wound regeneration as demonstrated using an improved rat excisional model.

\section{Materials and methods}

\subsection{Materials}

Bovine skin gelatin, 3-(4,5-dimethylthiazol-2-yl)-2,5-diphenyl tetrazolium bromide (MTT reagent), Hoechst 33342, 2-(4-amidinophenyl)-1H-indole-6-carboxamidine (DAPI), phalloidin-tetramethylrhodamine B isothiocyanate (phalloidin-TRITC), phenazine methosulfate (PMS), Triton X-100, zinc acetate dihydrate were purchased from SigmaAldrich. 3-(4,5-dimethylthiazol-2-yl)-5-(3-carboxymethoxyphenyl)-2-(4-sulfophenyl)-2Htetrazolium (MTS reagent) was purchased from Promega. $\mathrm{CuSO}_{4} \times 5 \mathrm{H}_{2} \mathrm{O}, \mathrm{MnCl}_{2} \times 4 \mathrm{H}_{2} \mathrm{O}$, $\mathrm{CoCl}_{2} \times 6 \mathrm{H}_{2} \mathrm{O}$, glutaric dialdehyde (GDA), $p$-formaldehyde, $\beta$-nicotinamide adenine dinucleotide (disodium salt hydrate), sodium pyruvate, sodium borohydride were produced by Acros Organics. Citrus pectin (classic CM 201) was produced by Herbstreith\&Fox.

Anti-Cytokeratin 10 antibody [EP1607IHCY] (Alexa Fluor® 647) (Abcam, ab194231) and CellTracker Green CMFDA Dye (Thermo Fisher Scientific), isoflurane (Abbott Laboratories) were used. Histological stains were obtained from BioVitrum (Russia). Reagents and consumables for cell culturing were purchased from Paneco (Russia). Ultrapure water (18.2 M $\Omega \times \mathrm{cm}$, Milli-QAdvantageA10, MerckMillipore) was used to prepare aqueous solutions and buffers. 


\subsection{Preparation of cryogels}

Cryogels were produced from bovine skin gelatin as described previously [35] with some modifications. Aqueous solutions of gelatin and pectin were initially prepared by dissolving the biopolymers in isotonic saline upon heating at $60{ }^{\circ} \mathrm{C}$. Stock solutions of GDA (25 wt\%) and transition metal (TM) salts $(0.1 \mathrm{M})$ were used. The reaction solution contained gelatin (2.5 wt\%), GDA (0.25 wt\%), pectin $(0.1 \mathrm{wt} \%)$ and TM $(0.04-5 \mathrm{mM})$. The mixture was carefully stirred and poured into a glass Petri dish as a reactor, which was further placed in a cooling thermostat at a temperature of $-12^{\circ} \mathrm{C}$ for $4 \mathrm{~h}$. Then the reaction mixture was transferred into a freezer $\left(-18^{\circ} \mathrm{C}\right)$ and additionally kept for $24 \mathrm{~h}$. The product was thawed at room temperature, treated with $5 \mathrm{mM}$ sodium borohydride solution to reduce the labile azomethine bonds in the cross-linked gelatin network and then carefully washed with water to finally obtain $3 \mathrm{~mm}$ thick cryogel films. The cryogels were stored in $20 \%$ ethanol solution in the fridge.

\subsection{Element analysis of cryogels}

The cryogels were washed with ultrapure water and freeze-dried. Inductively coupled plasma mass spectrometry (ICP-MS) analysis was performed on an iCAP Qc system (Thermo Fisher Scientific). The samples were dissolved in a mixture of 1 part of $38 \% \mathrm{HCl}$ and 9 parts of $68 \% \mathrm{HNO}_{3}$ (ultra-pure grade). $\mathrm{HCl} / \mathrm{HNO}_{3}$ mixture alone was used as a blank solution. The samples were decomposed in hermetic PTFE vials in a microwave oven Mars 6 (CEM Corporation) at $210^{\circ} \mathrm{C}$. The final solution was diluted by ultrapure water and $\mathrm{HCl}$; overall acid concentration was maintained at $2 \%$. Internal In standard was added to analyzed solutions at a final concentration of $5 \mathrm{ppb}$. The mass-spectrometer was pre-calibrated using multi-element standards in the range of concentration 1-100 ppb. The data were presented as mean $\pm \operatorname{SD}(\mathrm{n}=3)$.

Micro X-ray fluorescent ( $\mu$-XRF) analysis was performed on a M4 Tornado analyzer (Bruker) with a rhodium X-ray tube (30 W) and the point size of $25 \mu \mathrm{m}$. Dried cryogel membranes were attached to the sample stage, and $\mu$-XRF spectra from the upper surface were recorded with a $4 \mu \mathrm{m}$ step under vacuum. Based on the spectra, 2D maps of the samples were depicted where an individual color and its intensity corresponded to an element and its content. Back color designated lack of element(s) or hollow spaces. 


\subsection{Evaluation of swelling and viscoelastic properties of cryogels}

The cryogel membranes were cut into square pieces $1 \times 1 \mathrm{~cm}$ randomly selected for the analysis. The samples were weighed in three states as: (i) fully hydrated cryogels $\left(\mathrm{m}_{1}\right)$, (ii) partially hydrated cryogels after removing water with filter paper $\left(\mathrm{m}_{2}\right)$, (iii) dried materials $\left(\mathrm{m}_{0}\right)$. Prior drying the cryogels were equilibrated with ultrapure water. Then the samples were kept in air circulating oven at a temperature of $80^{\circ} \mathrm{C}$ for $3 \mathrm{~h}$ until mass stabilization (variation between measurements was $\leq 0.1 \%$ ). To assess swelling properties of the cryogels, relative water content of in macropores (here named as capillary water (CW)) and polymerbound water $(\mathrm{PW})$ were calculated using formulas: $\mathrm{CW} \%=\left(\mathrm{m}_{1}-\mathrm{m}_{2}\right) / \mathrm{m}_{1} \times 100 \%$ and $\mathrm{PW} \%$ $=\left(m_{2}-m_{0}\right) / m_{1} \times 100 \%$. An analytical balance with accuracy of $0.1 \mathrm{mg}$ was used. The data were presented as mean \pm SD $(n \geq 3)$.

Rheological properties of fully hydrated cryogels were analyzed on a Discovery hybrid rotational rheometer DHR-2 (TA Instruments). The measurements were performed at $37{ }^{\circ} \mathrm{C}$ using strain sweep test in the range from 0.01 to $100 \%$ ( $1 \mathrm{~Hz}$ frequency) and frequency sweep test in the range from 0.01 to $100 \mathrm{~Hz}$ (1\% strain amplitude). The data were processed with a Trios V3.1 software (TA Instruments).

\subsection{LSCM and SEM analysis of cryogels}

The fully hydrated unstained cryogels $(1 \times 1 \mathrm{~cm}$ samples) were analyzed using laser scanning confocal microscopy (LSCM) on a LSM 780 microscope (Carl Zeiss) with argon laser excitation (488 nm). Autofluorescence of cross-linked gelatin was detected to visualize structure of the cryogels. For scanning electron microscopy (SEM), the samples were freezedried and coated with $15 \mathrm{~nm}$ conductive layer (Au-Pd alloy) by cathode sputtering on a Q 150T ES sputter-coater (Quorum Technologies). The SEM analysis was carried out on a high-resolution field emission scanning electron microscope Merlin (Carl Zeiss) at an accelerating voltage of $5 \mathrm{kV}$ and a probe current of $300 \mathrm{pA}$.

\subsection{In vitro study}

Human skin fibroblasts (HSF) were isolated as described previously [36] and used at early passages. HSF were cultured aseptically in $\alpha$-MEM containing $10 \%$ fetal bovine serum, $2 \mathrm{mM}$ L-glutamine, $100 \mathrm{U} / \mathrm{mL}$ penicillin, $100 \mu \mathrm{g} / \mathrm{mL}$ streptomycin at $37^{\circ} \mathrm{C}$ in humidified air atmosphere with $5 \% \mathrm{CO}_{2}$. The cytotoxic effect of zinc ions towards HSF was evaluated by 
1 means of the MTT assay in the range of serially diluted TM concentrations from 6500 to $0.0015 \mu \mathrm{M}$ (culturing time was $72 \mathrm{~h}$ ). Ultrapure water was added as a negative control. Cell viability was determined by measuring optical absorption of the reduction product of MTT (formazan) relative to control untreated cells (100\% viability). GraphPad Prism 5 software was used to fit concentration-viability relationships and calculate corresponding halfmaximal inhibitory concentrations $\mathrm{IC}_{50}$. The data were presented as mean \pm SD.

HSF migration into and proliferation within cryogels was studied as follows. The cells were seeded onto a 24-well plate and cultured until sub-confluent monolayer was formed. The cryogel samples $(1 \times 1 \mathrm{~cm})$ were pre-incubated in Hanks' balanced salt solution (HBSS) containing concentrated penicillin (5 kU/mL) and streptomycin $(5 \mathrm{mg} / \mathrm{mL})$ for $1 \mathrm{~h}$ for additional decontamination. Then the samples were washed and equilibrated with excess full $\alpha$-MEM and transferred into aspirated wells to cover HSF monolayer. The pre-treatment of cryogels with a concentrated penicillin/streptomycin solution (50X) prevented medium contamination upon cell culturing. $1 \mathrm{~mL}$ of fresh $\alpha$-MEM was added into each well, and the cells were cultured with cryogels during 9 days. The culture medium was changed every 3 days.

\subsection{Cell detection within cryogels}

Following culturing, the matrices were transferred into new wells without cells. For lactate dehydrogenase (LDH) assay, the cryogels were washed with phosphate-buffered saline (PBS) and incubated in $0.5 \mathrm{~mL}$ PBS containing 1\% Triton X-100 and $1 \mathrm{mM}$ NaF for 1 $\mathrm{h}$ to lyse cells. The cell lysates were diluted 10 times in Tris buffer (0.05 M, pH 7.3) followed by addition of NADH (2.2 mM) and sodium pyruvate (10 mM). Then decrease in optical absorption of NADH $(\lambda=340 \mathrm{~nm})$ was detected on an Infinite 200 PRO microplate analyzer (Tecan). The decrement of the optical signal at the maximum reaction rate was presented as a measure of LDH activity. The MTS assay was performed as follows. The matrices in a 24well plate were rinsed with PBS followed by addition of $0.5 \mathrm{~mL}$ per well of culture medium supplemented with MTS/PMS according to Promega's recommendation. The samples were kept for $1 \mathrm{~h} 30 \mathrm{~min}$ in a $\mathrm{CO}_{2}$-incubator, then colored product of MTS reduction by viable cells (formazan) was registered at $490 \mathrm{~nm}$ on an Infinite 200 PRO microplate analyzer. Optical values from control wells containing the same medium and cell-free cryogels were subtracted. The data were presented as mean \pm SD. 
For LSCM visualization the matrices with HSF were fixed with 4 wt $\%$ p-formaldehyde.

2 The cells were pre-stained with CellTracker Red CMTPX Dye (5 $\mu \mathrm{g} / \mathrm{mL})$ or post-stained 3 with phalloidin-TRITC (50 $\mu \mathrm{g} / \mathrm{mL}$ ). The nuclei were labelled with Hoechst 33342 (5 $\mu \mathrm{g} / \mathrm{mL})$. LSCM images were acquired on a LSM 780 confocal microscope by optical sectioning of different representative areas of the matrices.

\subsection{Wound healing study}

8

\subsubsection{Animals}

Adult male Wistar rats (18 animals, $336 \pm 38$ g) were received from Vivarium of Academy of Medical and Technical sciences (Russia). Animal care was performed according to European regulations on the protection of experimental animals (Directive 2010/63/UE) and current Russian regulations (No. 742 from 13.11.1984, Ministry of Education and Science). The animals were housed at a temperature of $20 \pm 3^{\circ} \mathrm{C}$ and a humidity of $65 \pm 10 \%$. The surgical study was approved by the Institutional Ethical Review Board of the Kazan Federal University.

\subsubsection{Excisional wound model}

Rats were subjected to inhalation anesthesia with 2.5\% isoflurane using an Eickemeyer evaporator equipped with a DeVilbiss oxygen concentrator. The animals were shaved, cleansed with $70 \%$ ethanol solution, then two circles were outlined as a template for excision (Fig. 6). Full thickness skin excisions were made, taking out the underlying subcutaneous muscle. The excisions were $12 \mathrm{~mm}$ in diameter and c.a. $2.5 \mathrm{~mm}$ in depth with c.a. $2 \mathrm{~cm}$ distance between wound edges. To prevent wound closure due to constriction, round silicone splint (internal $\varnothing=12 \mathrm{~mm}$, external $\varnothing=25 \mathrm{~mm}$, thickness $0.5 \mathrm{~mm}$ ) was applied around the wound and fixed to skin using a sterile skin stapler ApposeTM ULC 35W (Covidien) (Fig. 6). The wounds were disinfected by rinsing with $0.01 \%$ myramistine solution (LLC Infamed, Russia) and washed with sterile isotonic solution.

The cryogel membranes were cut into round pieces $10 \mathrm{~mm}$ in diameter, treated with penicillin $(5 \mathrm{kU} / \mathrm{mL}) /$ streptomycin $(5 \mathrm{mg} / \mathrm{mL})$ for additional decontamination and washed with sterile isotonic solution to remove excess antibiotics. The wounds were dressed with the cryogels, and then adhesive gas permeable polyurethane film Hydrofilm ${ }^{\circledR}$ (Paul Hartmann AG) was fixed on the silicone splint to decrease wound drying and contamination. Compared 
samples were applied onto different sides of the same animal with alternating location (right and left sides).

\subsubsection{Visual and histological evaluation}

Wound images were taken using a DP-M17 USB digital microscope. The animals were sacrificed at days 3, 7, and 14 after treatment. Skin and surrounding tissues in the wound zone were dissected. The explants were fixed in $4 \% p$-formaldehyde solution in PBS at room temperature for $48 \mathrm{~h}$, washed, dehydrated in a graded series of ethanol solutions (50, 70, 90, 96 and 100\%) and treated in toluene. The tissues were embedded in paraffin blocks and cut on a microtome HM 355S (Thermo Fisher Scientific) into thin sections (7 $\mu \mathrm{m})$. Hematoxylineosin (HE) and Mallory staining was performed to evaluate regenerated tissues. The area and density of collagenous tissues having blue color were determined from representative images from the central area of wound (day 3, 7) using an Image J software. Immunofluorescent staining of the wound tissues (day 14) was performed using Alexa Fluor ${ }^{\circledR} 647$ labelled anticytokeratin 10 antibody and DAPI according to Abcam protocols on a LSM 780 confocal microscope.

\section{Results}

\subsection{Characterization of transition metal-doped cryogels}

Divalent transition metals (TM): $\mathrm{Zn}, \mathrm{Cu}, \mathrm{Mn}$ and Co were entrapped in cross-linked gelatin based cryogels as detailed in section 2.2. The TM concentration in the reaction solution varied in the range $0.04-5 \mathrm{mM}$. Small pectin additive was used (4\% of gelatin weight) to assist TM binding to the gelatin cryogel. The TM-gelatin cryogels had been produced in the form of films and have a similar appearance to that of the metal-free gelatin cryogel (Fig. S1) but different physicochemical characteristics (see section 3.2.).

The weight content of TM in washed and freeze-dried cryogels have been analysed by the ICP-MS (Table 1). The cryogels modified with $\mathrm{Zn}, \mathrm{Cu}, \mathrm{Mn}(1 \mathrm{mM})$ contained comparable amounts of the TM component: 2.8, 3.1 and $2.2\left(\times 10^{3} \mathrm{ppm}\right)$, respectively. The cobalt content in the Co-gelatin cryogel was almost $0.9 \times 10^{3} \mathrm{ppm}$, i.e. approximately 3.2 times lower compared with other TM. Only trace amounts of TM were detected in the blank metal-free cryogel (averagely $\sim 2 \mathrm{ppm}$ ). 
In our study we focused on a more detailed analysis of the Zn-doped cryogels in view of 2 established wound healing properties of zinc ions [26, 27]. The Zn content in biomaterials 3 almost linearly increased (c.a. $0.1-11.8 \times 10^{3} \mathrm{ppm}, \mathrm{r}^{2}=0.9982$ ) with increase of initial metal 4 concentration in the reaction solution (0.04-5 mM) (Table 1), suggesting good TM-binding capacity of the cryogel in the concentration range. Incubation of the Zn-doped cryogel (1 $\mathrm{mM}$ ) in solution for 10 days didn't show a significant washing out of the TM from the biomaterial. In addition, the possibility of introducing two metals, such as $\mathrm{Zn}$ and $\mathrm{Cu}$, in TMgelatin cryogel was assessed. The two TM were simultaneously entrapped in the cryogels $\left(1.7 \times 10^{3}\right.$ and $2.6 \times 10^{3} \mathrm{ppm}$ for $\mathrm{Zn}$ and $\mathrm{Cu}$, respectively), however, with partial decrease in the TM content compared with the single-component variants (by $39.7 \%$ and $17.5 \%$, respectively) attributed to competing of the metals for binding cites in the polymer network of cryogel (Table 1).

Table 1. Metal content in freeze-dried gelatin cryogels doped with transition metals according to ICP-MS. Mean \pm SD are presented $(n=3)$. The values for introduced metals are highlighted.

\begin{tabular}{|c|c|c|c|c|}
\hline \multirow{2}{*}{$\begin{array}{l}\text { Metal concentration in } \\
\text { reaction solution }\end{array}$} & \multicolumn{4}{|c|}{ Metal content in cryogel (ppm) } \\
\hline & $\angle \mathrm{n}$ & $\mathrm{cu}$ & IVIn & Lo \\
\hline $0.04 \mathrm{mM} \mathrm{Zn}$ & $113.2 \pm 1.3$ & 1.3 & 0.7 & $<\mathrm{DL}$ \\
\hline $0.2 \mathrm{mM} \mathrm{Zn}$ & $489.7 \pm 6.3$ & 0.5 & 0.2 & 2 \\
\hline $1 \mathrm{mM} \mathrm{Zn}$ & $2840.7 \pm 11.3$ & 1.1 & 0.2 & $<\mathrm{DL}$ \\
\hline $5 \mathrm{mM} \mathrm{Zn}$ & $11755.4 \pm 13.2$ & 0.5 & 0.2 & $<2 \mathrm{DL}$ \\
\hline $1 \mathrm{mM} \mathrm{Zn*}$ & $2196.4 \pm 25.9$ & $<2 \mathrm{DL}$ & 3.9 & 0.3 \\
\hline $1 \mathrm{mM} \mathrm{Zn**}$ & $2773.7 \pm 19.3$ & 0.8 & 0.4 & $<\mathrm{DL}$ \\
\hline $1 \mathrm{mM} \mathrm{Zn,} 1 \mathrm{mM} \mathrm{Cu}$ & $1673.8 \pm 4.8$ & $2584.6 \pm 10.7$ & 7.9 & 1 \\
\hline $1 \mathrm{mM} \mathrm{Cu}$ & 7.5 & $3133.4 \pm 57.3$ & 0.4 & $<\mathrm{DL}$ \\
\hline $1 \mathrm{mM} \mathrm{Mn}$ & 7.6 & 1.1 & $2216.6 \pm 39.3$ & $<\mathrm{DL}$ \\
\hline $1 \mathrm{mM}$ Co & 5.8 & 0.4 & 0.2 & $851.1 \pm 1.2$ \\
\hline
\end{tabular}

*: without pectin additive;

**: cryogel was stored in alcohol solution for 10 days. 
The $\mu$-XRF spectrometry confirmed effective incorporation as well as homogeneous

2 distribution of $\mathrm{Zn}$ in the TM-gelatin cryogel (Fig. 1). Among major elements detected, the

3 sulphur signal of cysteine residues in gelatin polypeptides provided good normalization for

$4 \quad \mathrm{Zn}$ quantification in the cryogels (Fig. 1c). It should be noted that apparent discrete

5 distribution of $\mathrm{Zn}$ in the doped cryogel (Fig. 1d) resulted from uneven porous surface of the

6 sample, and the zinc signal generally coincided with the sulphur signal in the maps (data not

7 shown).

8 The metal-free cryogel contained increased amount of calcium which was effectively 9 replaced by zinc ions in the TM-doped cryogel (Fig. 1c). Cumulative $\mathrm{Zn} / \mathrm{S}$ weight ratio in the Zn-doped cryogels $\left(2 \mathrm{~cm}^{2}\right)$ was as follows $\left(\times 10^{-3}\right)$ : $185(0.2 \mathrm{mM}), 686(1 \mathrm{mM}), 664(1 \mathrm{mM}$

11 after 10-day storage in alcohol solution). These results are in good agreement with the ICP12 MS data (Table 1).
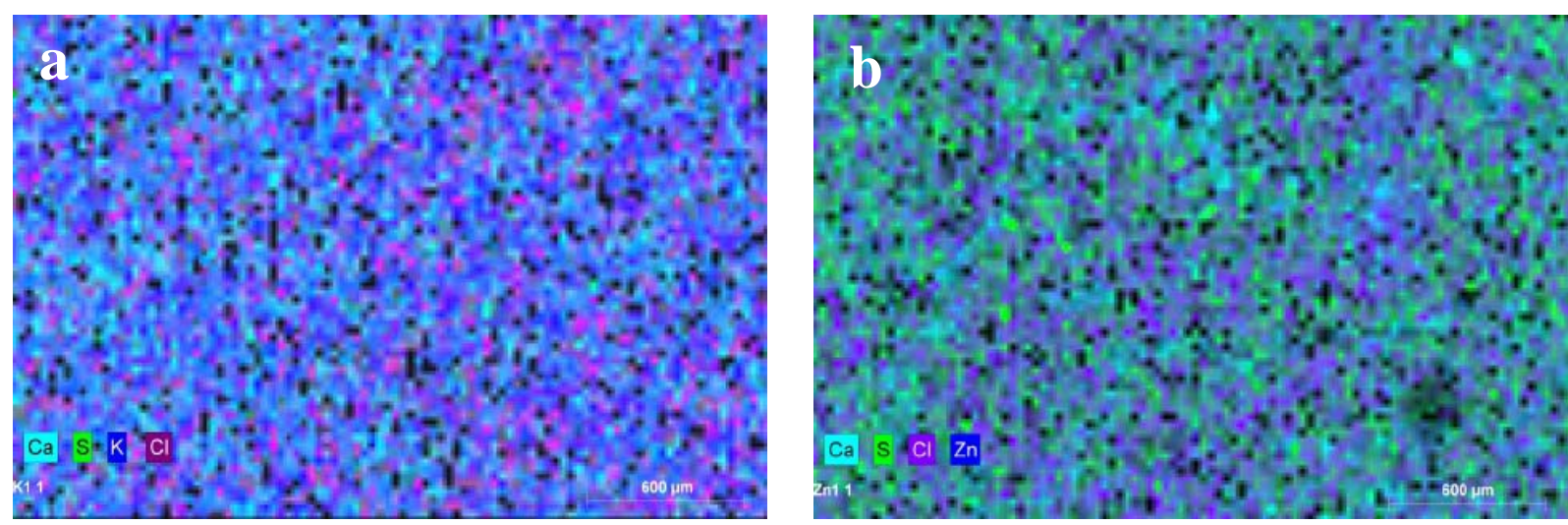

Spectrum: Non-doped cryogel

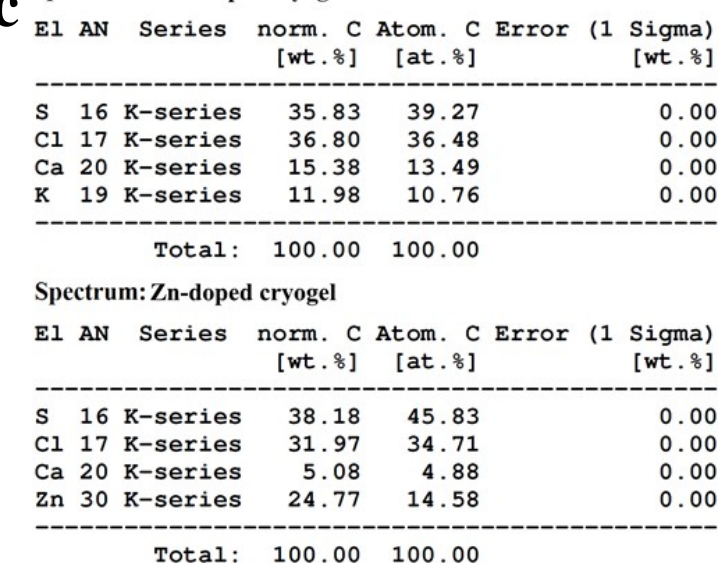

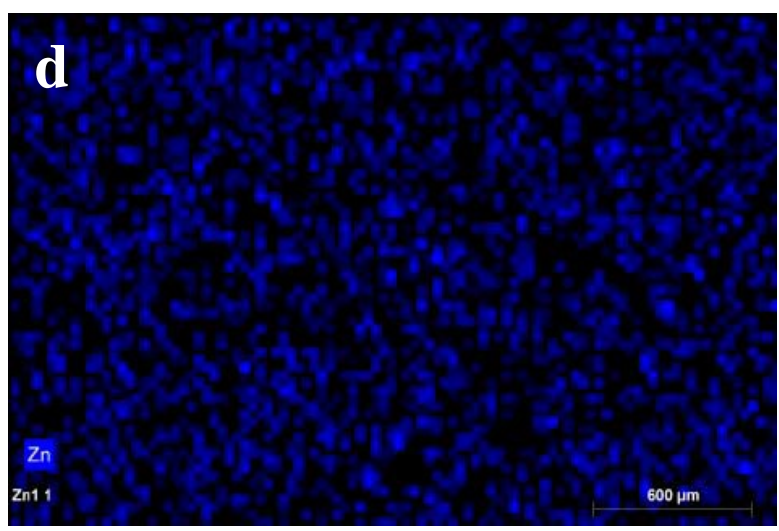

13 Fig. 1. Representative $\mu$-XRF data for non-doped and Zn-doped (1 mM) cryogels: mapping 14 of (a, b) major elements, (d) Zn alone and (c) cumulative content of the elements.

15 Lyophilized cryogels with total area of $2 \mathrm{~cm}^{2}$ were analysed. 


\section{3.2. Physicochemical characterization of Zn-doped cryogels}

3

4

5

6

7

8

\subsubsection{Porous structure}

According to SEM analysis of freeze-dried biomaterials, the metal-free cryogel had large interconnected pores, which were tens of microns in size, and thin walls of cross-linked polymer network (Fig. 2a). The Zn-doped cryogels (0.2-5 mM) exhibited different

morphology, particularly, wider polymer walls (Fig. 2b). According to LSCM analysis, the

hydrated non-doped cryogel showed somewhat less organized porous structure (Fig. 2c) compared with the Zn-doped cryogel (0.2 mM) with more defined cellular structure (Fig. 2d).

0 At increased $\mathrm{Zn}$ concentrations (1 and $5 \mathrm{mM}$ ) the cryogels with smaller pores were produced (Fig. S2).
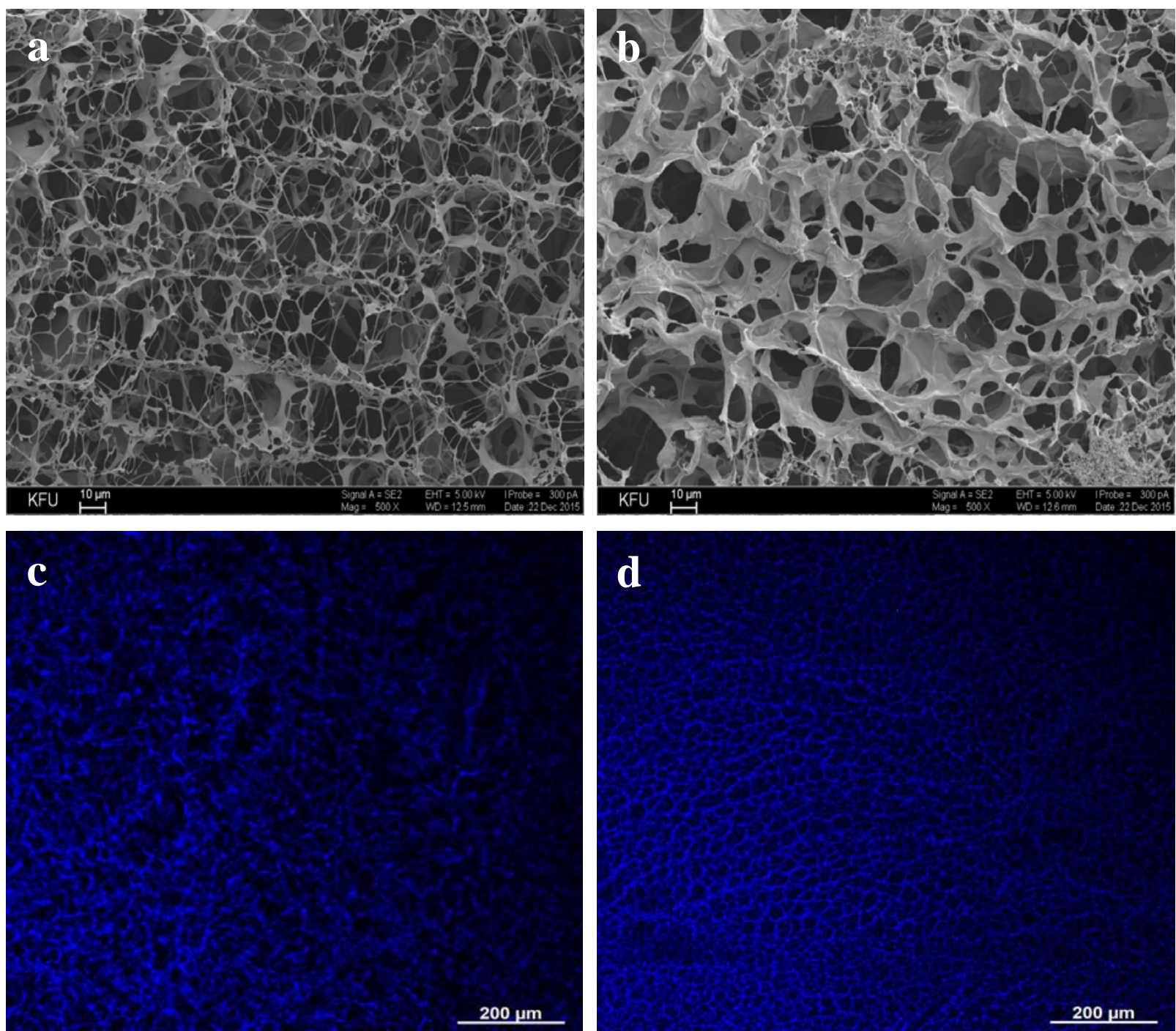
1 Fig. 2. Cryogel morphology: non-doped (left) and Zn-doped (0.2 mM) (right) cryogels: (a, b)

2 SEM and (c, d) LSCM.

\section{$3 \quad$ 3.2.2. Swelling and rheological properties}

The cryogels have weakly bound water in the large pores, capillary water (CW), which can be easily removed by squeezing out or absorbing, and a polymer-bound water (PW) retained in the polymer network (cryogel 'walls'). The relative amounts of CW and PW (\%) in fully hydrated cryogels were estimated (see section 2.4.). CW\% in cryogels approximately corresponds to the volume content of large (CW-filled) pores.

The introduction of zinc ions in the reaction solution at a concentration of $0-5 \mathrm{mM}$ resulted in gradual decrease of the CW amount in cryogels from 90.0 to $81.1 \%$ (Fig. 3a), showing reduction of cryogel macro-pores. At the same time, the PW amount gradually increased from 8.8 to $17.6 \%$ with increase of Zn concentration in the cryogels (Fig. 3a), suggesting enhanced swelling of the polymer walls containing the TM dopant. Taken together, our data show that zinc ions contribute to the formation of gelatin cryogel network in a concentration dependent manner presumably by introducing additional interactions between biopolymer functional groups and TM. The increase of $\mathrm{Zn}$ content increases swelling ability of the polymer walls and consequently reduces the large pore size in the fully hydrated Zn-doped cryogels in accordance with LSCM data (Figs. 2 and S2).
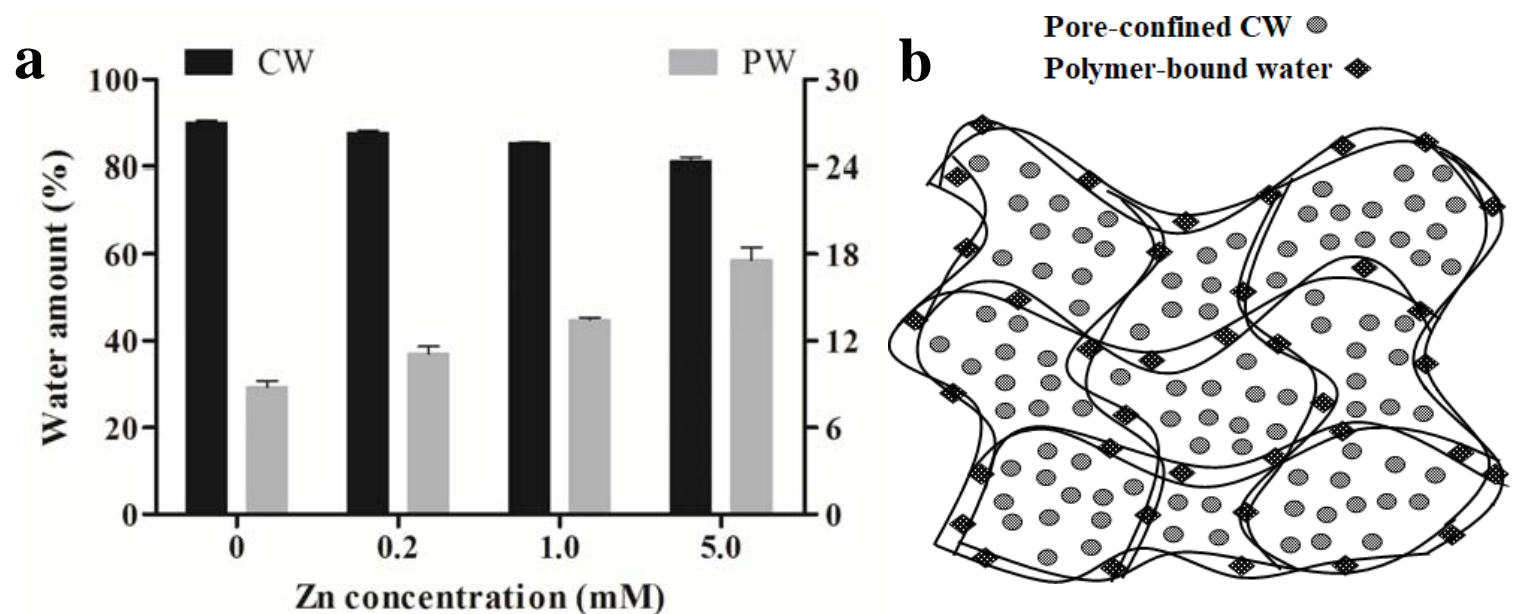

Fig. 3. Swelling properties of non-doped and Zn-doped cryogels. (a) Capillary water (CW) content (left Y axis) and polymer-bound water (PW) content (right Y axis) in fully hydrated cryogels. Mean \pm SD are presented $(n=3)$. (b) Scheme for distribution of CW and PW in the cryogel. 
According to rotational rheometry, the linear viscoelastic region (LVR) of the cryogels 2 gradually increased from 10.8 to $66.9 \%$ of oscillation strain for the $\mathrm{Zn}$ concentration of 0-5

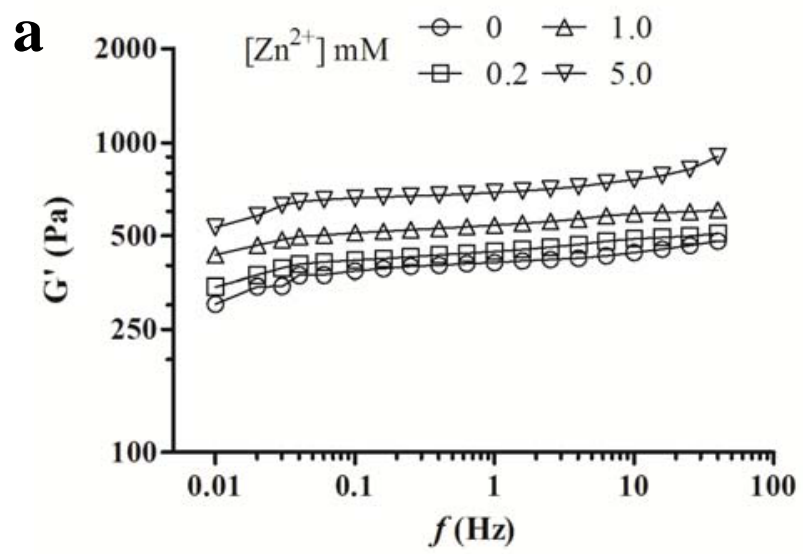

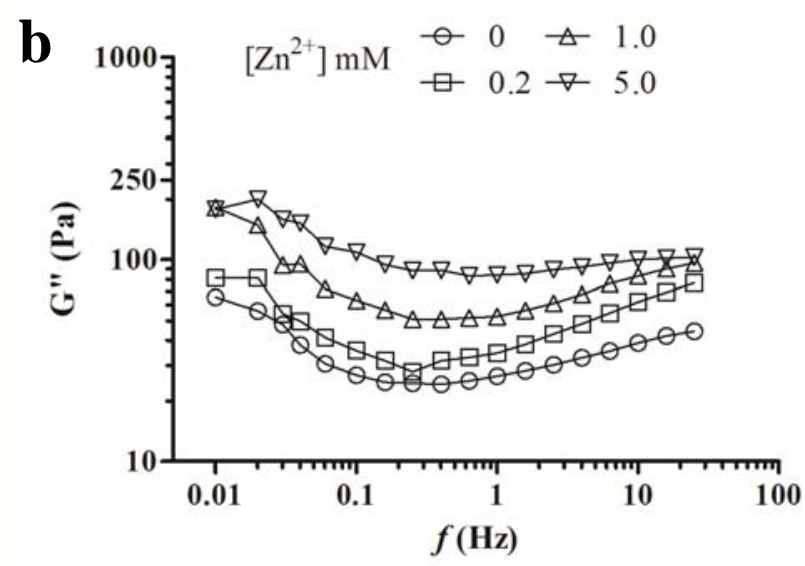

19 Fig. 4. Viscoelastic properties of non-doped and Zn-doped cryogels. Frequency sweep tests for (a) storage modulus G' (1\% strain amplitude) and (b) loss modulus G" (1\% strain amplitude) were used.

\subsection{Interaction of human skin fibroblasts with Zn-doped cryogels}


1 To assess the ability of biomaterials to support cell migration and proliferation, the

2 cryogels were cultured with human skin fibroblast (HSF) monolayers. The MTS assay (see

3 section 2.7.) provided reproducible detection of viable cells in the matrix. The corresponding

4 MTS signal was proportional to culturing time (Fig. 5a). This signal correlated well with the

5 LDH activity of cell lysates collected from the matrices (Fig. S4).

6 According to LCSM, HSF moved from the monolayers into the cryogel film and showed

7 typical spread morphology in the matrix (Fig. S5). The cells initially inhabited the bottom

8 side of the matrix, which was in contact with cell monolayer, and then further migrated

9 across the cryogel bulk towards to the upper side (Fig. S5). According to the MTS and LDH

10 assays, cell amount in the cryogel was proportional to culturing time (Figs. 5a, S4), allowing comparison of cell growth in different TM-doped cryogels.

12 The effect of Zn dopant on HSF proliferation in the cryogels was evaluated at day 6 (Fig. $135 \mathrm{~b}-\mathrm{f})$. In the concentration range studied only $5 \mathrm{mM} \mathrm{Zn}\left(11.8 \times 10^{3} \mathrm{ppm}\right.$ in the matrix) caused 14 considerable inhibition of cell growth (over 50\%). The conventional cytotoxicity analysis 15 (MTT assay, $72 \mathrm{~h}$ ) showed that soluble zinc ions exhibited IC50 value of $276 \pm 23 \mu \mathrm{M}$ for HSF. 16 The results suggest that the Zn-doped cryogels prepared using submillimolar TM 17 concentrations $\left(<3 \times 10^{3} \mathrm{ppm}\right.$ in the matrix) are generally compatible with mammalian cells. 18 The cryogel doped with intermediate $1 \mathrm{mM}$ Zn concentration was further selected to investigate in vivo effects of the Zn component in the TM-doped cryogel.
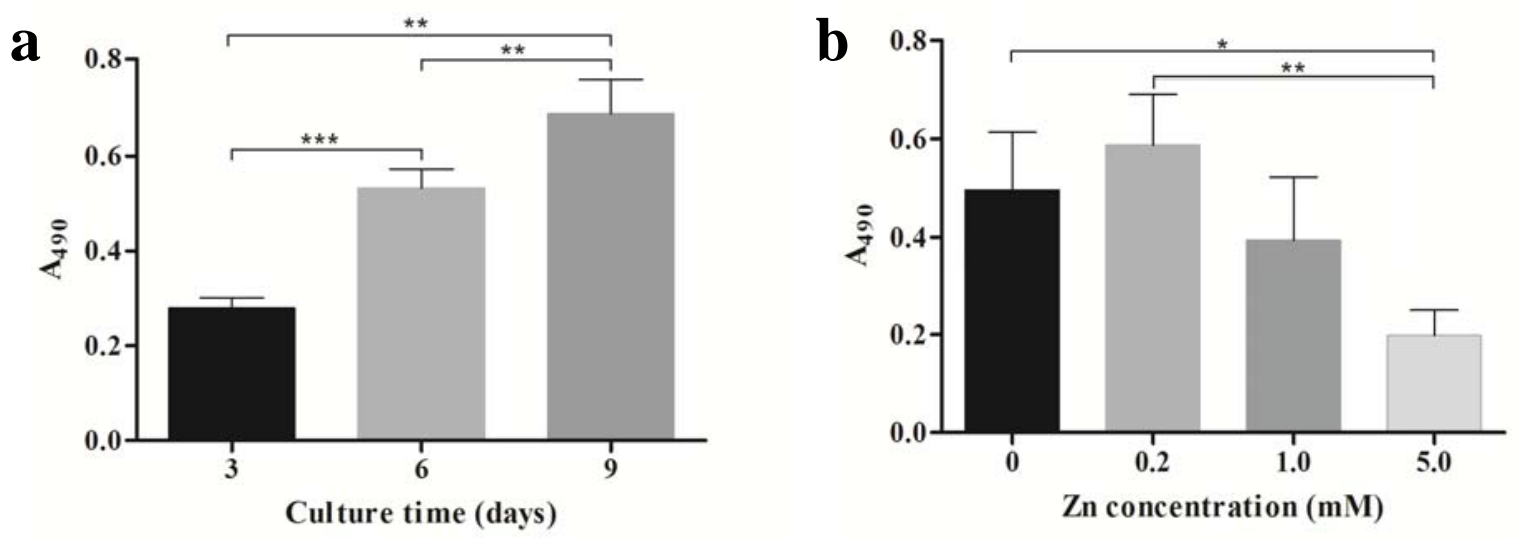

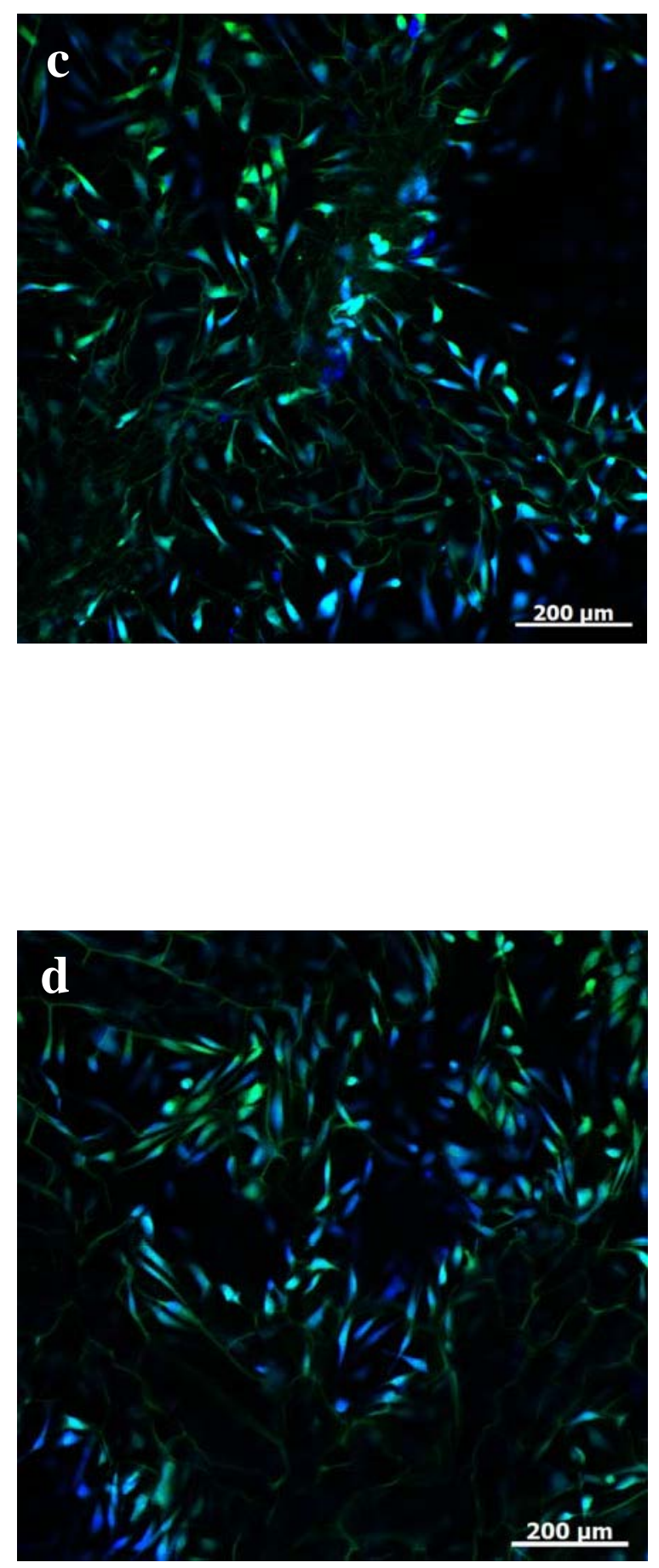

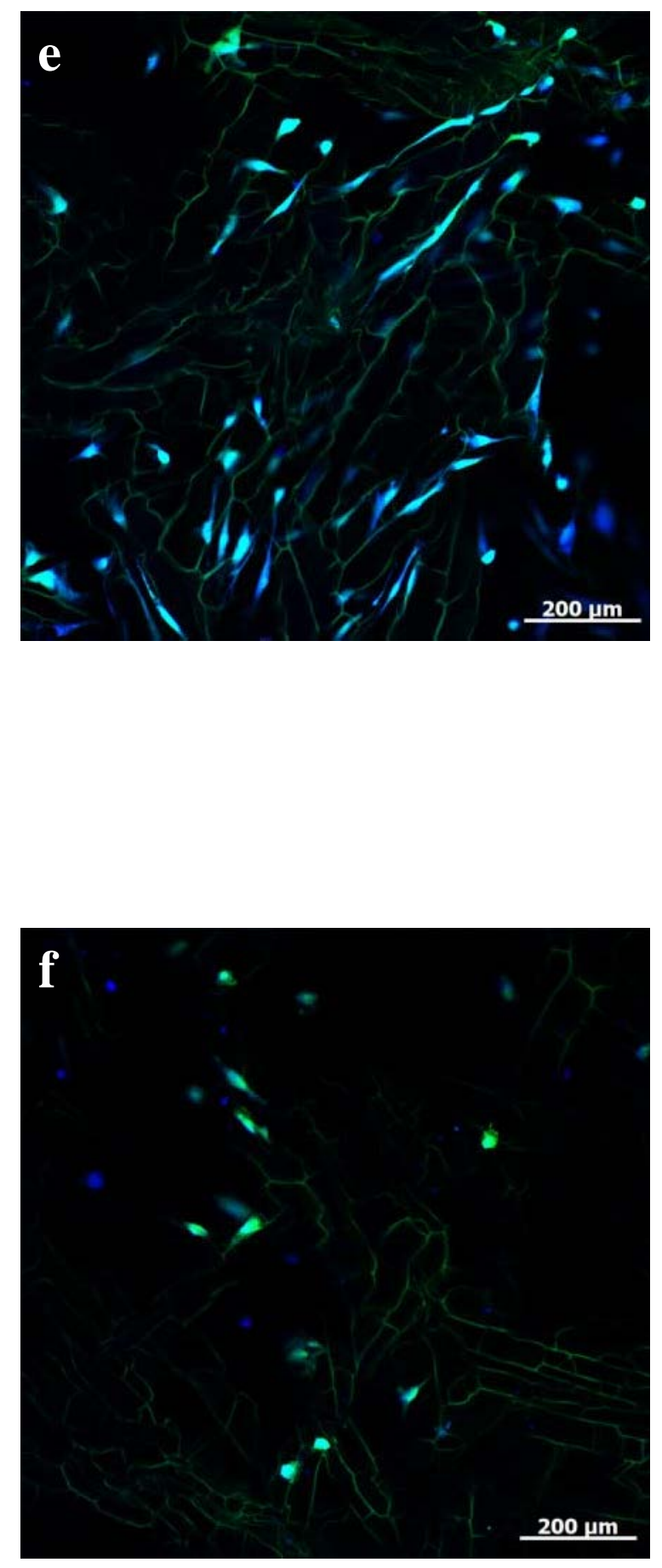

1 Fig. 5. Analysis of human skin fibroblasts (HSF) cultured with non-doped and Zn-doped 2 cryogels. (a) Detection of HSF in non-doped cryogel after culturing for 3, 6 and 9 days and 3 (b) effect of the Zn concentration on HSF amount in the doped cryogels at day 6 according to 4 MTS assay. For (b) mean \pm SD are presented, $n=4,{ }^{*} \mathrm{p}<0.05,{ }^{*} \mathrm{p}<0.01,{ }^{* * *} \mathrm{p}<0.001$. (c-f) 5 LSCM images of HSF in cryogels stained with Cell Tracker Green CMFDA and Hoechst 
6 33342: cells were cultured for 6 days in (c) non-doped or (d-f) Zn-doped cryogels with Zn 7 concentration $0.2,1$ and $5 \mathrm{mM}$, respectively.

8

9

10 3.4. Wound healing activity of Zn-doped cryogel

11 Excisional wounds were produced in rats as detailed in section 2.8.2. Both the metal-free 12 control and $\mathrm{Zn}(1 \mathrm{mM})$-doped cryogels were applied onto the wounds of the same animal 
1 (Fig. 6) to better identify effects of the TM dopant. All treated wounds were moist, without

2 evidences of scab and infection during observation. At day 3 after trauma the Zn-doped

3 cryogels were completely degraded, whereas only partial resorption of the non-doped

4 biomaterial occurred (Fig. 6c).

5

Fig. 7 shows representative pictures of hematoxylin-eosin (HE) and Mallory-stained

6 tissue cross-sections taken from the central area of wounds at day 3. Typical attributes of the

7 inflammatory/early proliferative phase of wound healing were observed for both variants of

8 cryogels. The wound tissues were subdivided into upper loose debris layer and an underlying

9 tissue (confined by two dashed lines), which laid above the regenerating subcutaneous muscle (panniculus carnosus) (Fig. 7). The latter tissue consisted of three main sublayers, as better seen for Mallory staining (Fig. 7b), attributed to inflammatory/fibrous tissues (vinous), thin intermediate tissue (orange) and growing collagenous tissue (blue) [39, 40].
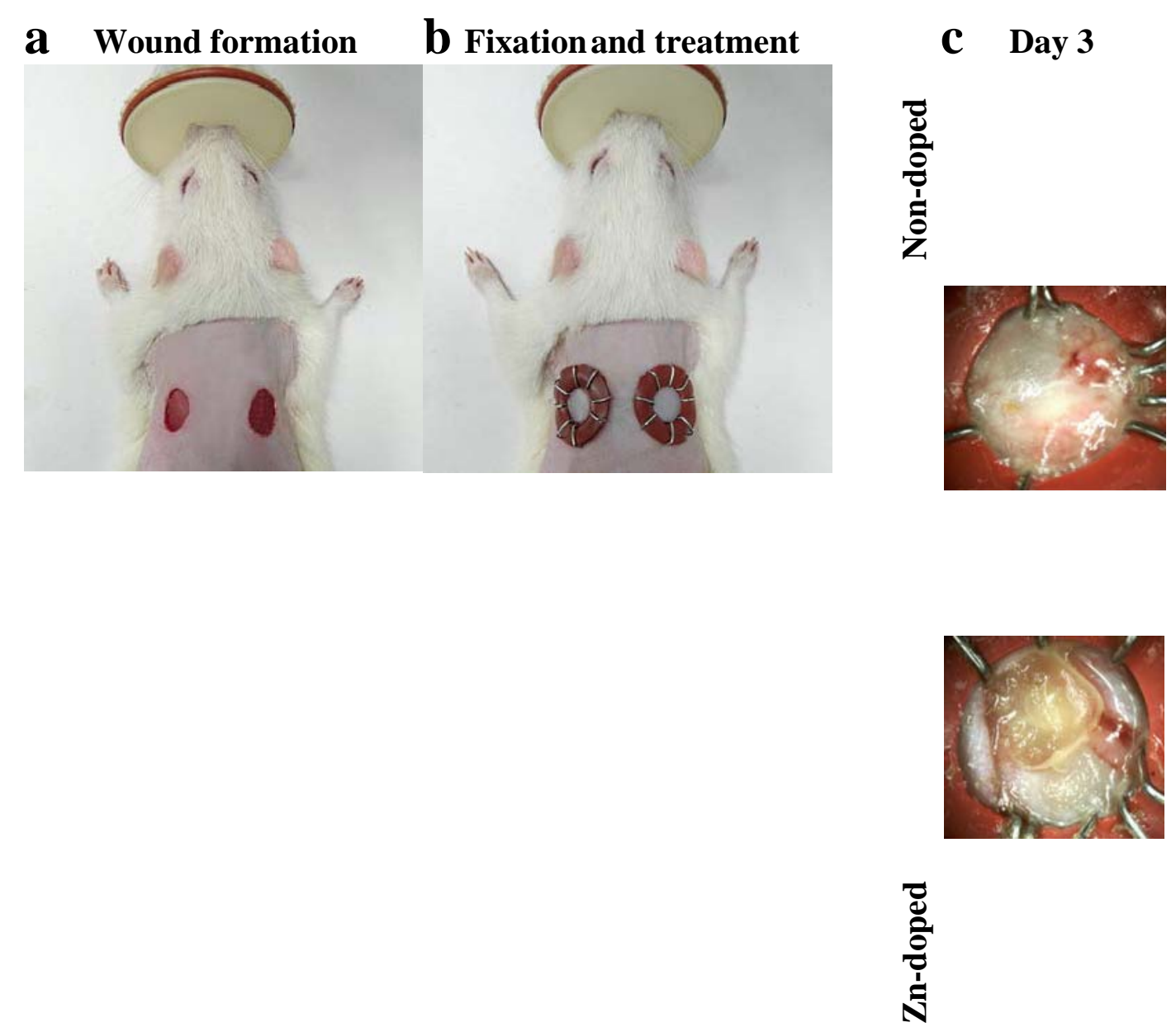

Fig. 6. Illustration of excisional wound model: (a) two full-thickness symmetrical wounds (12 $\mathrm{mm}$ in diameter) were introduced, (b) immobilized by silicone splints along wound edges and covered by hydrated cryogel films (10 mm in diameter); (c) Pictures of the wounds treated with non-doped and Zn-doped cryogels at day 3. In (c) fixating staples randomly shifted due 
17 to intrinsic mobility of the rat skin.

18

The Zn-doped cryogel exhibited distinct effects on regenerating tissues compared with 20 the TM-free cryogel. In the presence of $\mathrm{Zn}$, the debris layer was reduced and easily detached; 21 the upper sublayer was thinner, more structured and contained considerably less amount of 22 infiltrating leucocytes (Fig. 7). Furthermore, the underlying growing tissue was significantly 23 thicker when the Zn-doped cryogel was applied (blue sublayers in Fig. 7d vs. b with the mean 24 thickness of $593 \pm 83$ and $247 \pm 76 \mu \mathrm{m}$, respectively) $\left({ }^{*} \mathrm{p}<0.05\right)$. This kind of tissue is related to 
1 the granulation process and is known to be composed of newly formed transient ECM,

2 mainly, collagenous tissue [40].

3 Further formation of ECM and vessel-like structures filled with erythrocytes in

4 regenerating derma were detected at day 7 for both the non-doped and Zn-doped cryogels 5 (Fig. 8a-d), showing propagation of the proliferation (tissue growth) phase [41]. The relative 6 area and density of blue zones in the series of Mallory-stained sections attributed to collagen 7 fibers [40] were significantly, almost 2.6 and 2 times bigger, respectively, in the presence of 8 TM component (Fig. 8e, f). In the case of Zn-doped cryogel the formed tissues were more 9 infiltrated by spindle-shaped cells (Fig. 8d vs. b) generally attributed to fibroblasts, which are the main cells responsible for production of ECM components [40, 41].
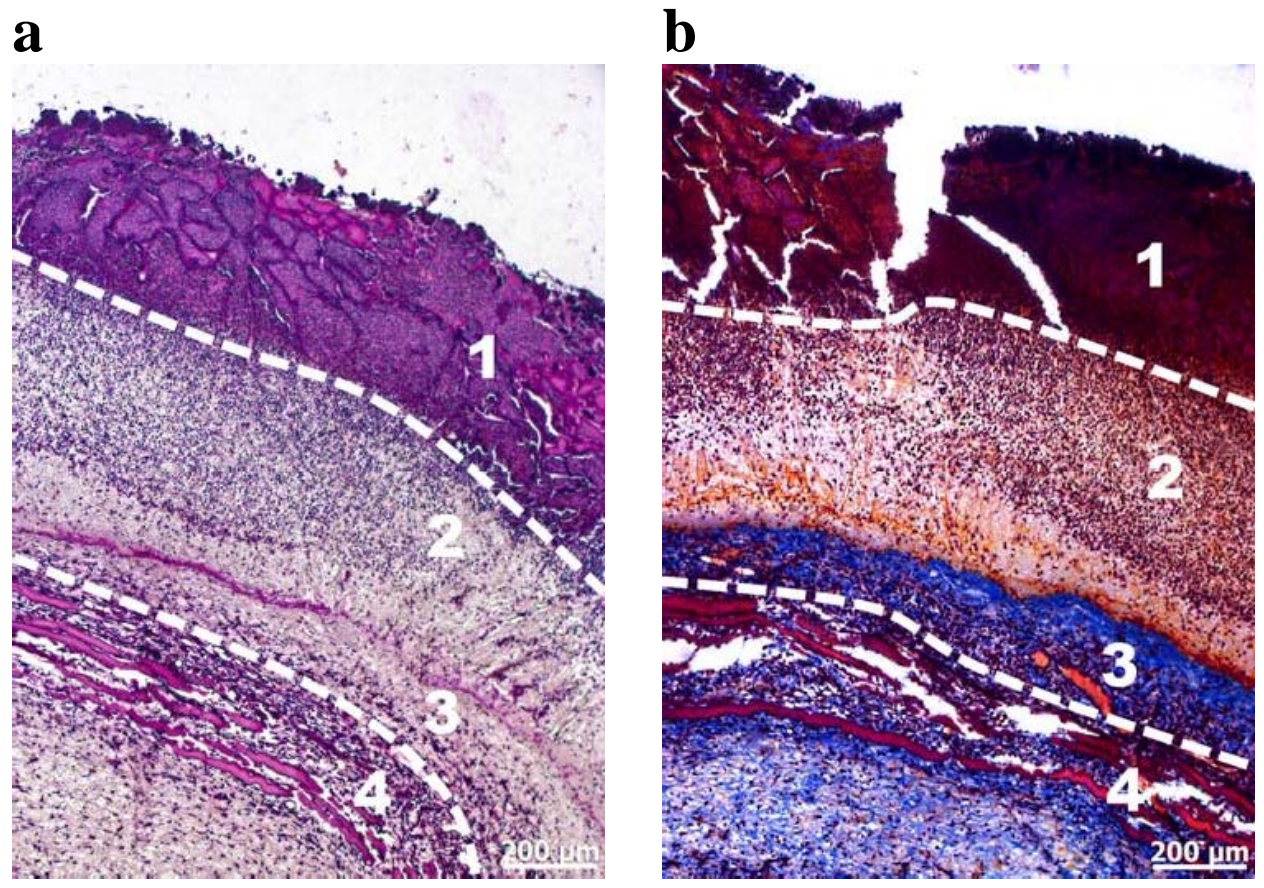

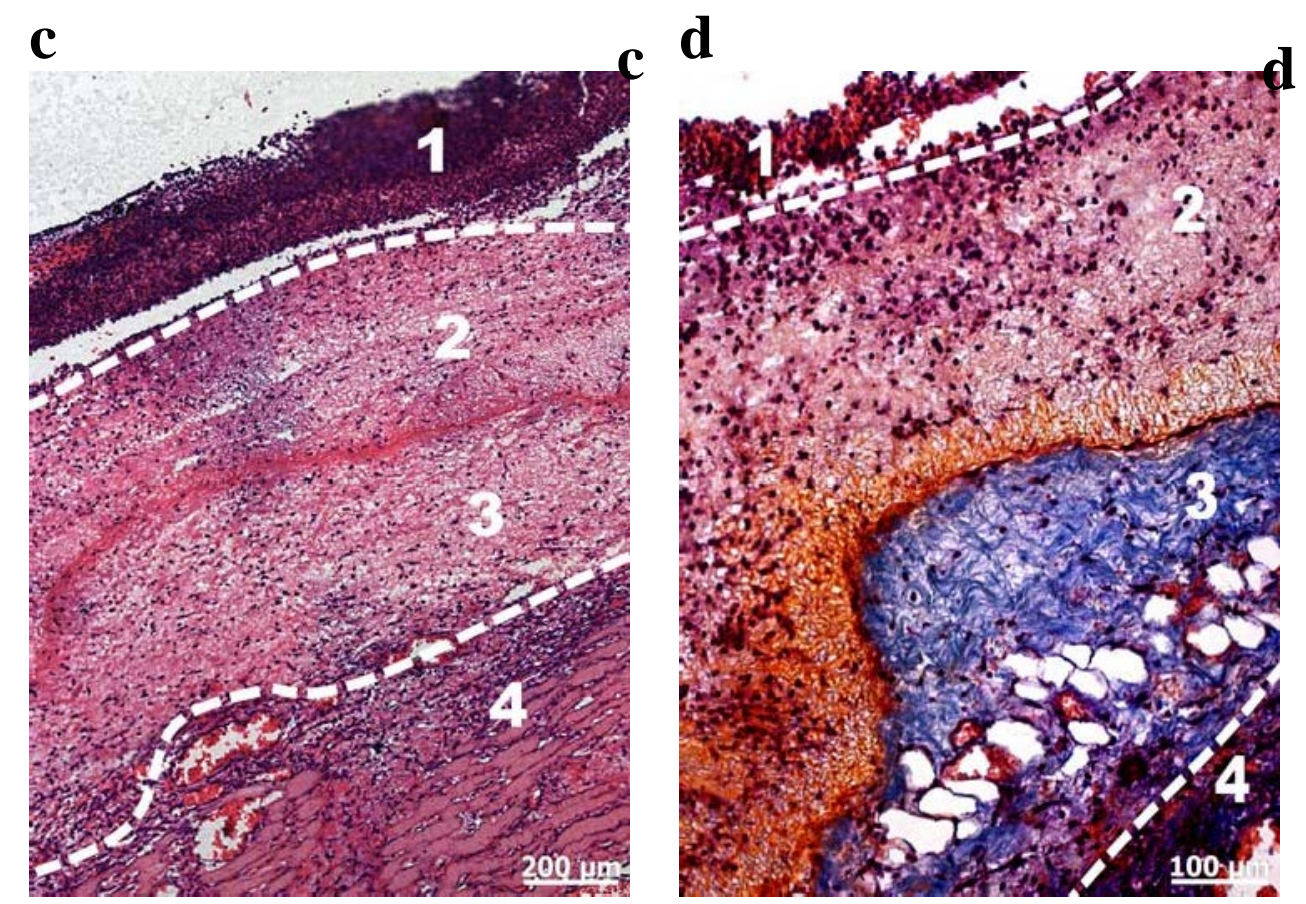

1 Fig. 7. Microphotographs of hematoxylin-eosin (left panel) and Mallory-stained (right panel)

2 tissue sections from wounds treated with (a, b) non-doped cryogel and (c, d) Zn-doped

3 cryogel at day 3 after trauma, showing debris layer (1), inflammatory/fibrous tissue (2),

4 collagenous tissue (3), and subcutaneous muscle (4).

5

6

a

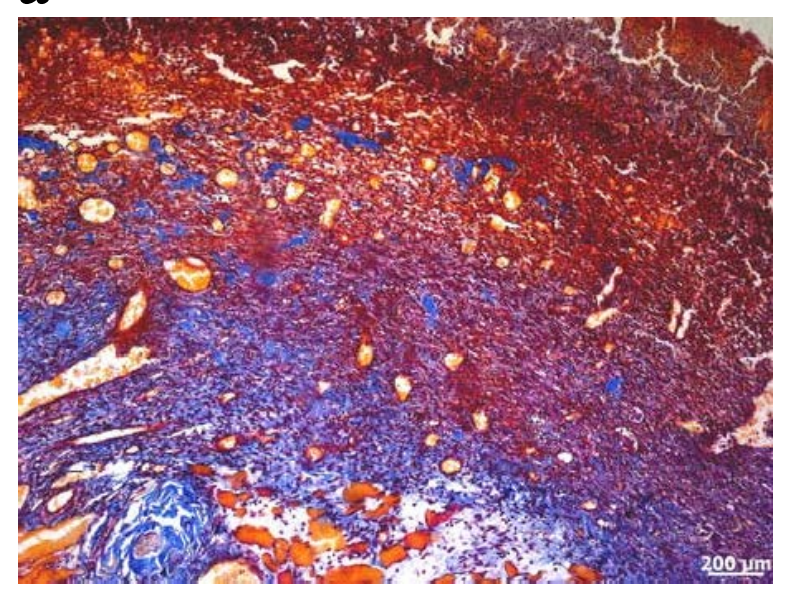

b

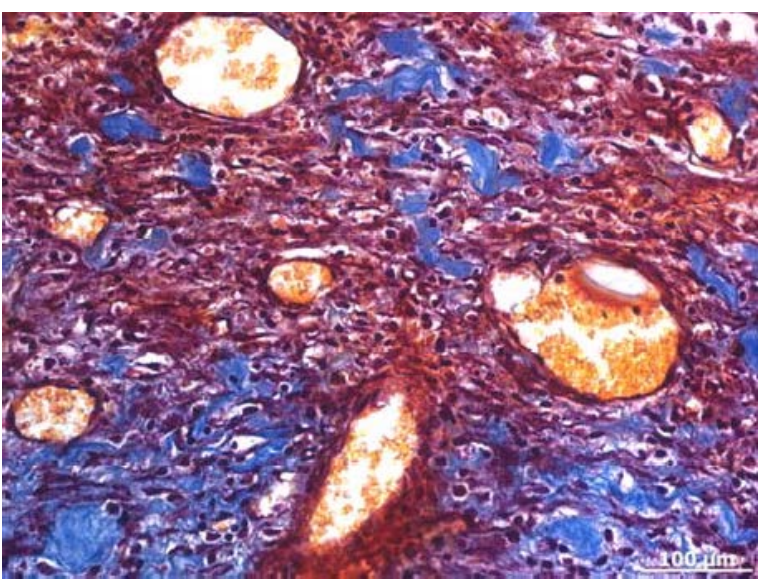



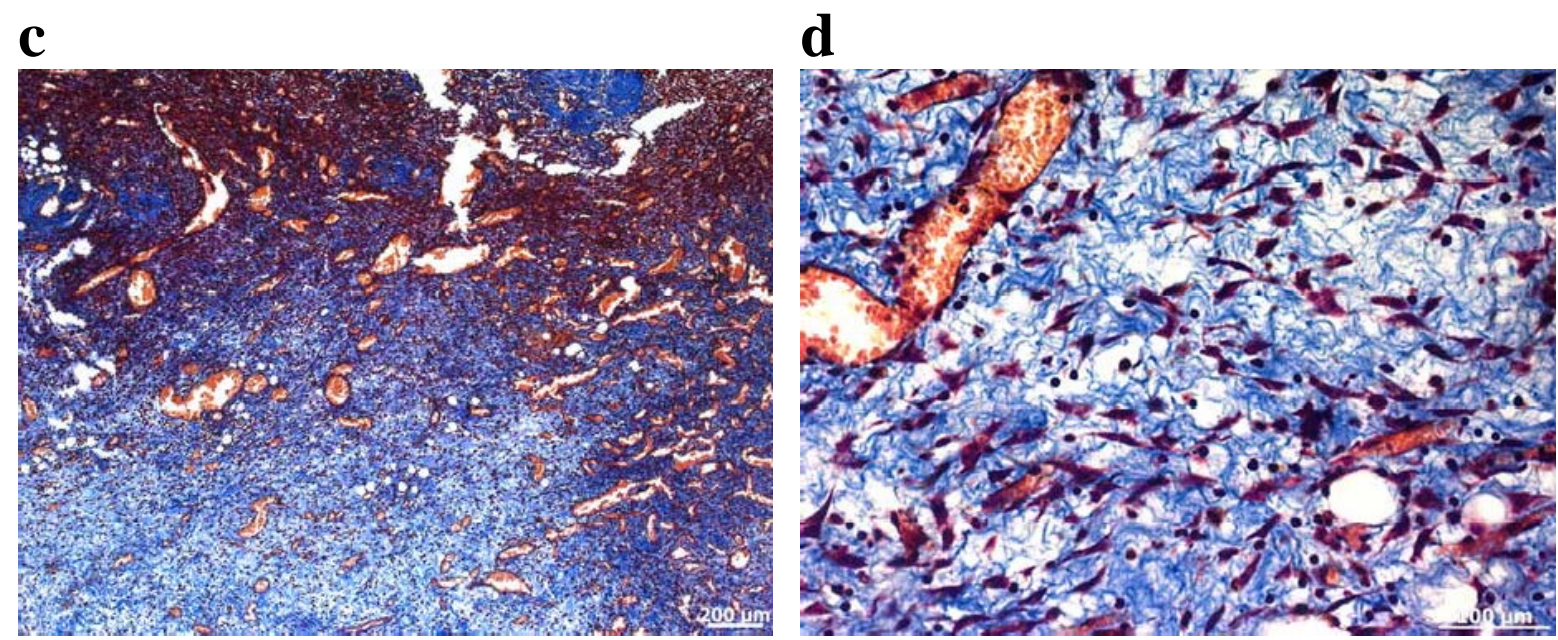

$\mathbf{e}$

\section{f}
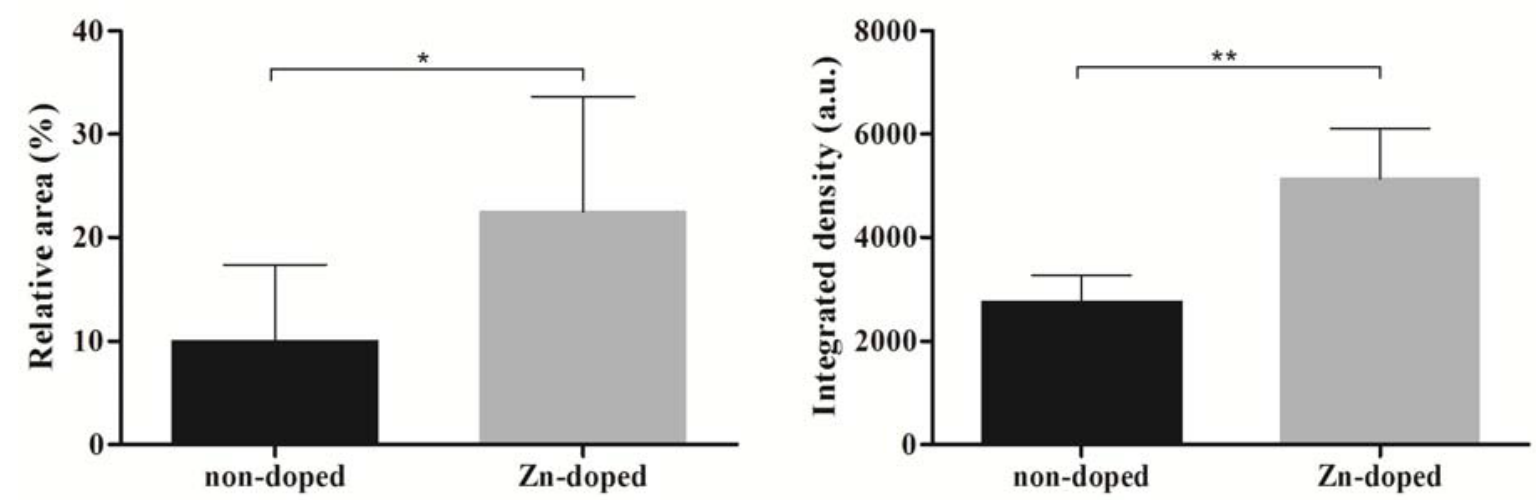

1 Fig. 8. Characterization of regenerating dermis in wounds treated with $(a, b)$ non-doped

2 cryogel and (c, d) Zn-doped cryogel at day 7 after trauma. (a-d) Microphotographs of

3 Mallory stained tissue sections at different magnifications; (e) relative area and (f) integrated

4 density of blue-colored collagenous tissues analyzed by ImageJ software $\left({ }^{*} \mathrm{p}<0.05\right.$, $5 \quad * * \mathrm{p}<0.01)$.

The late proliferating/remodeling phase could be identified at day 14 (Fig. 9). The multilayered epidermis of comparable thickness was formed for both cryogels applied. However, in the case of non-doped cryogel the epidermis was somewhat thinner and more organized into different sublayers (Fig. 9a, b). In particular, the germinal layer above the basement membrane with vertically elongated cells was clearly revealed both in the HE and DAPI stained sections (Fig. 9a, c). Furthermore, for the TM-free cryogel cytokeratin 10-positive cells were concentrated in a relatively thin layer (Fig. 9c), whereas for the Zn-doped cryogel these cells were more diffusely localized in the epidermis (Fig. 9d). These results indicate 
1 that treatment with the latter cryogel delays differentiation of the epidermis compared with 2 the TM-free cryogel, and this effect differed from that of the dermis, which was much more 3 structured when the Zn-doped cryogel was used (Fig. 9b vs. a).

a

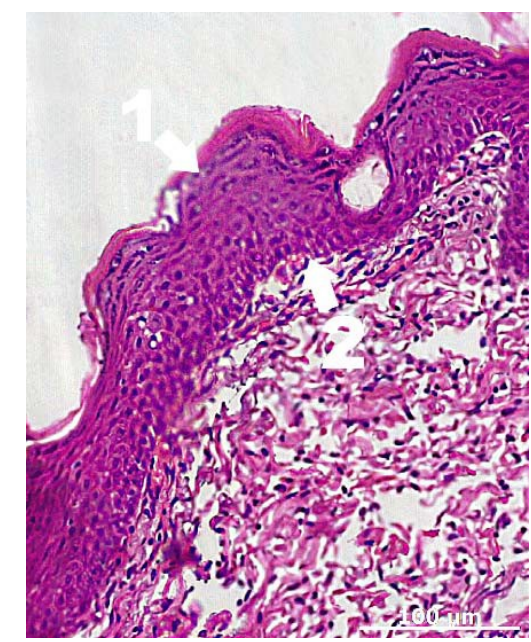

C

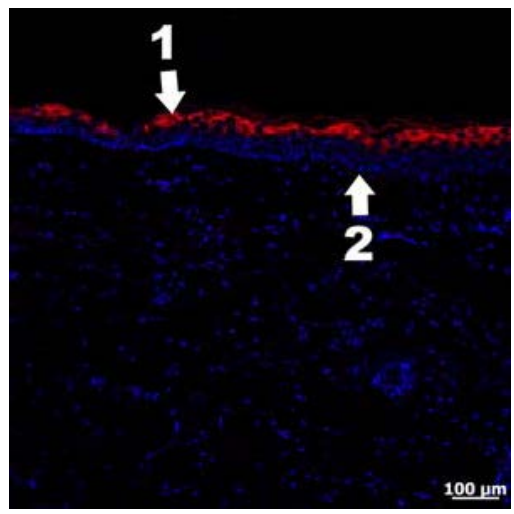

b

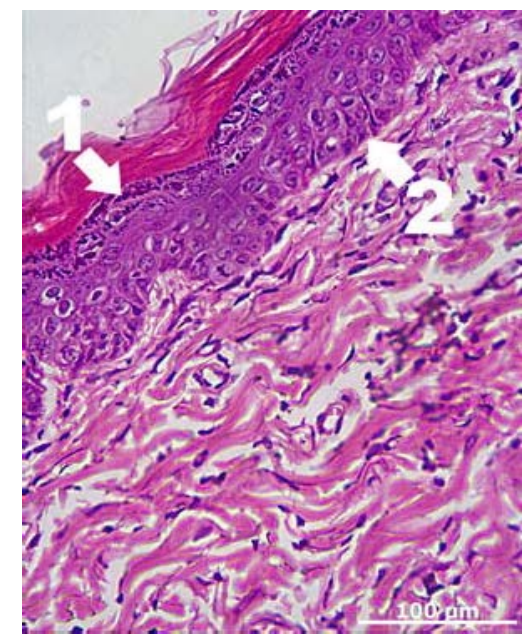

d

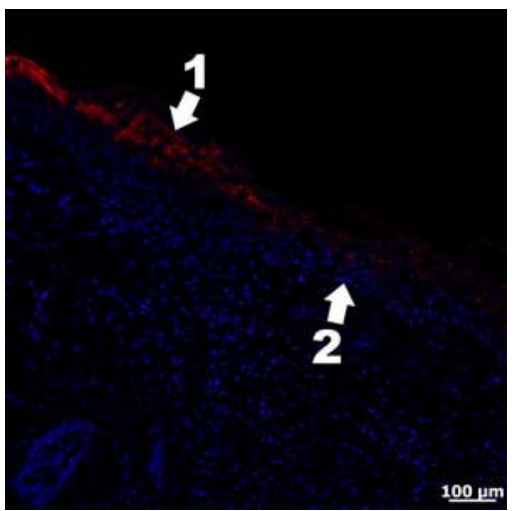

4 Fig. 9. Characterization of regenerating epidermis in wounds treated with (a, c) the nondoped cryogel and (b, d) Zn-doped cryogel at day 14 after trauma: (a, b) bright field microphotographs of HE stained tissue sections; (c, d) immunofluorescent detection of cytokeratin 10 (red). For (c, d) cell nuclei were stained with DAPI (blue).

\section{4. Discussion}

TM were studied both as a structural and active component of soft hydrogel biomaterials, which were meant for treating traumatic injuries. Cell-modulating properties of divalent Zn, $\mathrm{Cu}, \mathrm{Mn}$, and Co ions [16] were primarily addressed. Compared with recombinant biomacromolecules and peptides TM benefit from much higher stability and lower cost [16]. However, their therapeutic use together with biomaterials/scaffolds require the development of special safe and effective material formulations. Macroporous cryogels were tested as a promising type of tissue-engineered materials [42] additionally carrying bioactive TM. The 
1 cryogels were produced from gelatin, i.e. denatured collagen, which generally preserves

2 collagen primary structure and related properties [43] including metal-binding ability [44], while it lacks processing disadvantages and potential immunogenicity of native collagen preparations [43].

TM were incorporated into the gelatin based cryogel during the cryogelation. Galacturonic acid-rich polysaccharide, namely citrus pectin, which has a high affinity for divalent metals [45], was added to the cryogel composition $(0.1 \mathrm{wt} \%$ or $4 \%$ of gelatin weight). All metals were effectively retained in the gelatin network with pectin additive after washing and freeze-drying of the TM-doped cryogels (Table 1).

Both ionic and coordination interactions are expected to be involved in retention of the TM ions by the cryogel walls. Considering that the Zn content in pectin-free gelatin cryogel was just by $23 \%$ lower (Table 1), the prevailing gelatin component seems to play the crucial role in the TM binding. However, it was found that adding pectin provides more reproducible introduction of zinc ions in the gelatin cryogels (data not shown), suggesting certain auxiliary effect of the anionic polysaccharide on the TM binding to the matrix.

Potential binding sites for divalent metals in mammalian collagen chains include Glu, Asp, Gln, Asn, Cys residues (see the Uniprot database). Such sites participate in collagen biomineralization process upon collagen/hydroxyapatite matrix formation in bones [46]. Nitrogen-containing side groups of collagen chains such as Lys $\varepsilon$-amino group, His imidazole, Arg guanidino groups could be also involved in formation of coordination bonds with TM [44]. Divalent metals are known to participate in interaction of collagen sequences with other ECM and cell membrane components, e.g. integrin domains [47]. Recently, complexes of human-like recombinant collagen with $\mathrm{Ca}, \mathrm{Cu}$, and $\mathrm{Mn}$ were prepared and characterized. Chelates formed with the TM were shown to involve $\mathrm{C}-\mathrm{N}, \mathrm{C}=\mathrm{O}$ and $\mathrm{N}-\mathrm{H}$ groups of collagen [48].

An entrapment efficacy of TM within cryogels decreased as follows $\mathrm{Cu}>\mathrm{Mn}>\mathrm{Zn}>\mathrm{Co}$ (Table 1). TM interactions with the collagenous matrix may be affected by both TM characteristics, e.g. ion size, ionization potential, and polypeptide structure [44]. The TM contents found in the doped cryogels (Table 1) were comparable to those found in the demineralized bone and tendon matrices after incubation with the metal solutions [44]. In our study, almost linear relationship with Zn concentration in the reaction solution (Table 1) suggests that the sorption capacity of the cryogels lays within the concentration range studied or even exceeds it ( $\geq 5 \mathrm{mM}$ ). The results propose the possibility of controllable introduction 
1 simultaneously incorporated into the biomaterials within the concentration range as shown

2 for $\mathrm{Zn}$ and $\mathrm{Cu}$ (Table 1), which is of interest for combining bioactivity of different TM. In 3 addition to the ICP-MS, the $\mu$-XRF spectrometry was shown to be useful technique to study 4 relative content and distribution of TM along with other elements in biomaterials (Fig. 1).

The concentration-dependent effects of the $\mathrm{Zn}$ dopant on microstructure, swelling and rheological characteristics of the TM-doped cryogels were revealed (Figs. 2-4). These effects can be explained by the formation of non-covalent bonds between polymer chains in the hydrogel network by multivalent TM ions. The TM-mediated additional linking causes the increment in hydrogel component in proportion to the TM content. Consequently, this gradually increases the amount of PW (Fig. 3a), the gel G' and G" values (Fig. 4) and also decreases the amount of CW/macro-pore volume in the Zn-doped cryogels (Figs. 3a, S2).

As reported recently, introduction of $\mathrm{Ca}^{2+}, \mathrm{Fe}^{3+}$ and $\mathrm{Ag}^{+}$(1-4 mmol/g) into collagen/polyacrylate film altered the material structure and increased its tensile strength and barrier properties [49]. On the other hand, ion exchange removal of impurity of divalent metals from gelatin preparation was shown to affect formation of the biopolymer network, provide better EDC carbodiimide diffusion, and increase stability and strength of the crosslinked gel [50].

Early passage HSF were cultured in contact with cryogels and detected in the matrix using the MTS assay (Fig. 5a, b). Considering sensitivity of the tetrazolium compounds towards cellular metabolism [51] and matrix components [52], the LDH analysis of lysed HSF was additionally performed for cell detection in the cryogels (Fig. S4). Similar data were obtained in both MTS and LDH assays. The maximum growth rate of HSF within cryogel was observed during first 6 days of culturing, and it decreased at day 9 (Fig. 5a, S4). The corresponding doubling time for HSF in the matrix was c.a. 54 h. Insignificant increase / decrease in HSF proliferation were revealed in the presence of Zn dopant equivalent to 0.2 and $1 \mathrm{mM}$ Zn concentrations, respectively, compared with the non-doped cryogel (Fig. 5b). Higher $\mathrm{Zn}$ concentration of $5 \mathrm{mM}\left(11.8 \times 10^{3} \mathrm{ppm}\right.$ in the cryogel) caused a considerable cytotoxic effect of the matrix (Fig. 5b, f). Comparison of the Zn cytotoxic level with $\mathrm{IC}_{50}$ value of solubilized zinc ions ( $276 \mu \mathrm{M}$ or $18 \mu \mathrm{g} / \mathrm{mL}$ ) indicated almost 3 orders of magnitude lower effect of the matrix-bound Zn on HSF. Hence, only small part of incorporated zinc ions seems to be available to the cells upon culturing. Higher TM concentrations in TM-modified porous glass scaffolds were reported to be non-cytotoxic [[21],[22],[24]], indicating decreased availability of the doped metals in the solid materials. 
The cryogel with intermediate $\mathrm{Zn}$ concentration $\left(1 \mathrm{mM} / 2.8 \times 10^{3} \mathrm{ppm}\right)$ was tested as a wound healing biomaterial. An improved excisional model was used, in which two parallel splinted wounds were treated with different cryogel samples (Fig. 6). Such a model allows for more reliable comparison of topical formulations since it is less sensitive to variability in immune responses as well as to constriction effect in rodents which considerably affect wound healing [53]. In our study, the previous murine model [54] was implemented in rats with modifications (see section 2.8.2.) to provide more sparing defect area per animal weight, easier surgical procedure and handling.

The conditions of wounds management with the cryogels corresponded to the moist type of treatment [55]. In comparison with the non-doped, the Zn-doped cryogel exhibited faster resorption in contact with the wound bed, which was generally completed during 3 days (Fig. 6c). This could be explained by increased degradation of the cryogel by zinc-dependent proteases playing an important role in all phases of wound healing [26, 27]. The Zn amount used in the cryogel formulation was almost two orders higher than that the total TM content in normal rat skin (c.a. 46 ppm [56]). Local resorption and clearance of released soluble zinc ions are expected during wound healing to maintain skin homeostasis. To better compare the effect of biomaterials histological analysis was performed at earlier time points (3, 7, and 14 days) prior complete repair. The analysis showed that in the case of Zn-doped cryogel the wound tissues were in their later regeneration stage (Figs. 7-9).

It can be assumed that zinc ions accelerate passing the inflammatory/proliferation phase (Figs. 7 and 8) via different mechanisms, e.g. modulation of leucocyte activity in the wound bed [27, 28], activating matrix metalloproteinases [16], diminishing inflammatory reactions [28] and stimulating functional activity of fibroblasts [26, 27]. Mallory trichrome staining was used to analyze both structure and relative quantity of the collagenous tissues. The trichrome methods were earlier shown to provide consistent data with other assays based on hydroxyproline detection and immunostaining of collagen $[57,58]$.

According to Mallory staining [40], relative area and density of transient collagenous fibers in the regenerating dermis were almost two times higher in the presence of Zn dopant (Fig. 8e, f); and this agreed with increased number of fibroblast-like cells (Fig. 8d vs. b). At day 14, almost mature dermis was formed in the case of Zn-doped cryogel (Fig. 9b), however, in the absence of Zn dopant the newly formed dermis was still in its remodeling phase (Fig. 9a). This suggests that the zinc-mediated effects induced in early phases of wound 
In the case of Zn-doped cryogel the epidermis formation was somewhat delayed (Fig. 9) compared with the dermis regeneration Furthermore, somewhat better organization of epidermal cells, including germinal cells (contacting with the basement membrane), intermediate stratum spinosum cells and upper keratinized cells, was observed upon treatment with the TM-free cryogel (Fig. 9). However, direct stimulating activity of zinc ions on proliferation and differentiation of keratinocytes in vitro was previously reported [26]. Variation in the effect of Zn-doped and non-doped cryogels on epidermis structuration seemingly results from noticeable inhibition of constriction of the regenerating subcutaneous muscle by the former material as illustrated in Fig. S6. Such a constriction effect, which is more specific to rodents, is known to decrease wound area, thus indirectly promote ing surface closure and epithelization [55, 59]. In humans, excessive wound constriction by myofibroblasts could be involved in hypertrophic scar formation [60]. Our results demonstrate bioactive properties and enhanced wound healing activity of the Zn-doped gelatin cryogel. The exact mechanisms of regenerative activity of Zn- and other TM-doped cryogels require further investigation.

\section{Conclusions}

Our study shows that gelatin cryogels are a promising biomaterial formulation for carrying active transition metals. The pure TM, such as $\mathrm{Zn}, \mathrm{Cu}, \mathrm{Mn}, \mathrm{Co}$, can be stably incorporated into chemically cross-linked gelatin cryogels with pectin additive. The TM incorporation presumably involves multivalent binding of the metal ions to the polymer network of cryogels. The content of $\mathrm{Zn}$ ions attached to the cryogels varied from 0.1 to $11.8 \times 10^{3} \mathrm{ppm}$. The Zn dopant gradually alters the porous structure, swelling and rheological properties of the doped-cryogels in a concentration-dependent manner. Enhanced wound healing effect of the Zn-doped cryogel was established using improved rat excisional model. The $\mathrm{Zn}$ dopant increased cryogel biodegradation and accelerated skin regeneration. Wound treatment with the Zn-doped cryogel resulted in decreased leucocyte infiltration and increased generation of dermis components. Further development of effective cryogel based TM formulations, which specifically target different phases of tissue repair, could be envisaged. Our results demonstrate that TM-doped cryogels are of considerable interest for post-traumatic regeneration of soft tissues. 


\section{Acknowledgments}

3

4

5

6

7

8

9

10

This work was performed according to the Russian Government Program of Competitive Growth of the Kazan Federal University (KFU). Dr. Z. Siraeva, Dr. R. Kazakova (Institute of Fundamental Medicine and Biology, KFU); V. Vorobev, S. Kuznetcova (Interdisciplinary Center for Analytical Microscopy, KFU); L. Amirova (A. Butlerov Institute of Chemistry, KFU) are greatly acknowledged. Equipment of Interdisciplinary Centre for Shared Use (KFU) was used.

\section{References}

[1] A. W. C. Chua, Y. C. Khoo, B. K. Tan, K. C. Tan, C. L. Foo and S. J. Chong, Skin tissue engineering advances in severe burns: review and therapeutic applications, Burns Trauma, 4 (2016), 3

[2] D. Grinsell and C. P. Keating, Peripheral Nerve Reconstruction after Injury: A Review of Clinical and Experimental Therapies, Biomed Res Int, 2014 (2014), 13

[3] T. Hoshiba, H. Lu, N. Kawazoe and G. Chen, Decellularized matrices for tissue engineering, ExpertOpin BiolTH, 10 (2010), 1717-1728

[4] F. J. O'Brien, Biomaterials \& scaffolds for tissue engineering, Mater Today, 14 (2011), 88-95

[5] J.-A. Yang, J. Yeom, B. W. Hwang, A. S. Hoffman and S. K. Hahn, In situ-forming injectable hydrogels for regenerative medicine, Prog Polym Sci, 39 (2014), 1973-1986

[6] B. A. Blakeney, A. Tambralli, J. M. Anderson, A. Andukuri, D.-J. Lim, D. R. Dean and H.-W. Jun, Cell infiltration and growth in a low density, uncompressed three-dimensional electrospun nanofibrous scaffold, Biomaterials, 32 (2011), 1583-1590

[7] S. J. Hollister, Porous scaffold design for tissue engineering, Nat Mater, 4 (2005), 518 [8] S. Liu, H. Zhang, X. Zhang, W. Lu, X. Huang, H. Xie, J. Zhou, W. Wang, Y. Zhang, Y. Liu, Z. Deng and Y. Jin, Synergistic Angiogenesis Promoting Effects of Extracellular Matrix Scaffolds and Adipose-Derived Stem Cells During Wound Repair, Tissue Eng Part A, 17 (2010), 725-739 
1 [9] J. Kim, I. S. Kim, T. H. Cho, K. B. Lee, S. J. Hwang, G. Tae, I. Noh, S. H. Lee, Y. Park

2 and K. Sun, Bone regeneration using hyaluronic acid-based hydrogel with bone morphogenic

3 protein-2 and human mesenchymal stem cells, Biomaterials, 28 (2007), 1830-1837

4 [10] K. C. Rustad, V. W. Wong, M. Sorkin, J. P. Glotzbach, M. R. Major, J. Rajadas, M. T.

5 Longaker and G. C. Gurtner, Enhancement of mesenchymal stem cell angiogenic capacity

6 and stemness by a biomimetic hydrogel scaffold, Biomaterials, 33 (2012), 80-90

7 [11] W. Ji, Y. Sun, F. Yang, J. J. J. P. van den Beucken, M. Fan, Z. Chen and J. A. Jansen,

8 Bioactive Electrospun Scaffolds Delivering Growth Factors and Genes for Tissue

9 Engineering Applications, Pharm Res, 28 (2011), 1259-1272

[12] K. G. Sreejalekshmi and P. D. Nair, Biomimeticity in tissue engineering scaffolds

through synthetic peptide modifications-Altering chemistry for enhanced biological response, J Biomed Mater Res A, 96A (2011), 477-491

[13] C. G. Fraga, Relevance, essentiality and toxicity of trace elements in human health, Mol Aspects Med, 26 (2005), 235-244 [14] F.H. Zulkifli, F.S.J. Hussain, S.S. Zeyohannes, M.S.B. Rasad, M.M. Yusuff. A facile synthesis method of hydroxyethyl cellulose-silver nanoparticle scaffolds for skin tissue engineering applications, Mater Sci Eng C, 79 (2017), 151-160 [15] A. Azam, A. S. Ahmed, M. Oves, M. S. Khan, S. S. Habib and A. Memic, Antimicrobial activity of metal oxide nanoparticles against Gram-positive and Gram-negative bacteria: a comparative study, Int J Nanomedicine, 7 (2012), 6003-6009

[16] V. Mourino, J. P. Cattalini and A. R. Boccaccini, Metallic ions as therapeutic agents in tissue engineering scaffolds: an overview of their biological applications and strategies for new developments, J R Soc Interface, 9 (2012), 401-419

[17] J. P. Kehrer, The Haber-Weiss reaction and mechanisms of toxicity, Toxicology, 149 (2000), 43-50

[18] R. A. Akhmadishina, E. V. Kuznetsova, G. R. Sadrieva, L. R. Sabirzyanova, I. S. Nizamov, G. R. Akhmedova, I. D. Nizamov and T. I. Abdullin, Glutathione salts of O,Odiorganyl dithiophosphoric acids: Synthesis and study as redox modulating and antiproliferative compounds, Peptides, 99 (2018), 179-188 [19] P. D. Ray, B.-W. Huang and Y. Tsuji, Reactive oxygen species (ROS) homeostasis and redox regulation in cellular signaling, Cell. Signalling, 24 (2012), 981-990 [20] M. Schäfer and S. Werner, Oxidative stress in normal and impaired wound repair, Pharmacol Res, 58 (2008), 165-171 
1 [21] C. Wu, Y. Zhou, W. Fan, P. Han, J. Chang, J. Yuen, M. Zhang and Y. Xiao, Hypoxia-

2 mimicking mesoporous bioactive glass scaffolds with controllable cobalt ion release for bone

3 tissue engineering, Biomaterials, 33 (2012), 2076-2085

4 [22] E. Quinlan, S. Partap, M. M. Azevedo, G. Jell, M. M. Stevens and F. J. O'Brien,

5 Hypoxia-mimicking bioactive glass/collagen glycosaminoglycan composite scaffolds to

6 enhance angiogenesis and bone repair, Biomaterials, 52 (2015), 358-366

7 [23] G. Borkow, J. Gabbay, R. Dardik, A. I. Eidelman, Y. Lavie, Y. Grunfeld, S. Ikher, M.

8 Huszar, R. C. Zatcoff and M. Marikovsky, Molecular mechanisms of enhanced wound

9 healing by copper oxide-impregnated dressings, Wound Repair Regen, 18 (2010), 266-275

[24] C. Wu, Y. Zhou, M. Xu, P. Han, L. Chen, J. Chang and Y. Xiao, Copper-containing mesoporous bioactive glass scaffolds with multifunctional properties of angiogenesis capacity, osteostimulation and antibacterial activity, Biomaterials, 34 (2013), 422-433 [25] L. Pickart, The human tri-peptide GHK and tissue remodeling, J Biomater Sci Polym Ed, 1419 (2008), 969-988 [26] P.-H. Lin, M. Sermersheim, H. Li, H. P. Lee, M. S. Steinberg and J. Ma, Zinc in Wound Healing Modulation, Nutrients, 10 (2017), 16 [27] A. B. G. Lansdown, U. Mirastschijski, N. Stubbs, E. Scanlon and M. S. Agren, Zinc in wound healing: Theoretical, experimental, and clinical aspects, Wound Repair Regen, 15 19 (2007), 2-16

[28] N. Gammoh and L. Rink, Zinc in Infection and Inflammation, Nutrients, 9 (2017), 624 and I. Banerjee, Cobalt doped proangiogenic hydroxyapatite for bone tissue engineering application, Mater Sci Eng C, 58 (2016), 648-658 [30] I.-H. Lee, H.-s. Yu, N. J. Lakhkar, H.-W. Kim, M.-S. Gong, J. C. Knowles and I. B. Wall, Development, characterisation and biocompatibility testing of a cobalt-containing titanium phosphate-based glass for engineering of vascularized hard tissues, Mater Sci Eng C, 33 (2013), 2104-2112

[31] P. V. Gnaneshwar, S. V. Sudakaran, S. Abisegapriyan, J. Sherine, S. Ramakrishna, M. H. A. Rahim, M. M. Yusoff, R. Jose and J. R. Venugopal, Ramification of zinc oxide doped hydroxyapatite biocomposites for the mineralization of osteoblasts, Mater Sci Eng C, 96 (2019), 337-346

32 [32] Y. Ramaswamy, C. Wu, H. Zhou and H. Zreiqat, Biological response of human bone cells to zinc-modified Ca-Si-based ceramics, Acta Biomater, 4 (2008), 1487-1497 
1 [33] A. Vengellur and J. J. LaPres, The Role of Hypoxia Inducible Factor $1 \alpha$ in Cobalt

2 Chloride Induced Cell Death in Mouse Embryonic Fibroblasts, Toxicol. Sci., 82 (2004), 6383646

4 [34] I. N. Savina, G. C. Ingavle, A. B. Cundy and S. V. Mikhalovsky, A simple method for 5 the production of large volume 3D macroporous hydrogels for advanced biotechnological, 6 medical and environmental applications, Sci Rep, 6 (2016),

7 [35] R. V. Shevchenko, M. Eeman, B. Rowshanravan, L. U. Allan, I. N. Savina, M. Illsley, 8 M. Salmon, S. L. James, S. V. Mikhalovsky and S. E. James, The in vitro characterization of 9 a gelatin scaffold, prepared by cryogelation and assessed in vivo as a dermal replacement in wound repair, Acta Biomater, 10 (2014), 3156-3166 [36] O. V. Tsepaeva, A. V. Nemtarev, T. I. Abdullin, L. R. Grigor'eva, E. V. Kuznetsova, R. A. Akhmadishina, L. E. Ziganshina, H. H. Cong and V. F. Mironov, Design, Synthesis, and Cancer Cell Growth Inhibitory Activity of Triphenylphosphonium Derivatives of the Triterpenoid Betulin, J Nat Prod, 80 (2017), 2232-2239 [37] S. Van Vlierberghe, P. Dubruel and E. Schacht, Effect of Cryogenic Treatment on the Rheological Properties of Gelatin Hydrogels, J Bioact Compat Polym, 25 (2010), 498-512 [38] M. Razavi, S. Hu and A. S. Thakor, A collagen based cryogel bioscaffold coated with nanostructured polydopamine as a platform for mesenchymal stem cell therapy, J Biomed Mater Res A, 106 (2018), 2213-2228 [39] M. Y. Wells, H. Voute, V. Bellingard, C. Fisch, V. Boulifard, C. George and P. Picaut, Histomorphology and Vascular Lesions in Dorsal Rat Skin Used as Injection Sites for a Subcutaneous Toxicity Study, Toxicol Pathol, 38 (2010), 258-266 [40] N. Lemo, G. Marignac, E. Reyes-Gomez, T. Lilin, O. Crosaz and D. M. D. Ehrenfest, Cutaneous reepithelialization and wound contraction after skin biopsies in rabbits: a mathematical model for healing and remodelling index, Vet. Arhiv, 80 (2010), 637-652 [41] N. S. Greaves, K. J. Ashcroft, M. Baguneid and A. Bayat, Current understanding of molecular and cellular mechanisms in fibroplasia and angiogenesis during acute wound healing, J Dermatol Sci, 72 (2013), 206-217 [42] T. M. A. Henderson, K. Ladewig, D. N. Haylock, K. M. McLean and A. J. O'Connor, 30 Cryogels for biomedical applications, J. Mater. Chem. B, 1 (2013), 2682-2695

31 [43] S. Gorgieva and V. Kokol, Collagen-vs. Gelatine-Based Biomaterials and Their 32 Biocompatibility: Review and Perspectives, Biomaterials Applications for Nanomedicine, 33 (2011), 17-52 
1 [44] J. A. Spadaro, R. O. Becker and C. H. Bachman, Size-specific Metal Complexing Sites

2 in Native Collagen, Nature, 225 (1970), 1134

3 [45] V. M. Dronnet, C. M. G. C. Renard, M. A. V. Axelos and J. F. Thibault,

4 Characterisation and selectivity of divalent metal ions binding by citrus and sugar-beet

5 pectins, Carbohydr Polym, 30 (1996), 253-263

6 [46] M. Jia, Y. Hong, S. Duan, Y. Liu, B. Yuan and F. Jiang, The influence of transition

7 metal ions on collagen mineralization, Mater Sci Eng C, 33 (2013), 2399-2406

8 [47] J. Bella and H. M. Berman, Integrin-collagen complex: a metal-glutamate handshake,

9 Structure, 8 (2000), R121-R126

[48] C. Zhu, Y. Sun, Y. Wang, Y. Luo and D. Fan, The preparation and characterization of novel human-like collagen metal chelates, Mater Sci Eng C, 33 (2013), 2611-2619

[49] Y. Ma, W. Wang, Y. Wang, Y. Guo, S. Duan, K. Zhao and S. Li, Metal ions increase mechanical strength and barrier properties of collagen-sodium polyacrylate composite films, Int J Biol Macromol, 119 (2018), 15-22 [50] Q. Xing, K. Yates, C. Vogt, Z. Qian, M. C. Frost and F. Zhao, Increasing Mechanical Strength of Gelatin Hydrogels by Divalent Metal Ion Removal, Sci Rep, 4 (2014), 4706 [51] D. Lobner, Comparison of the LDH and MTT assays for quantifying cell death: validity for neuronal apoptosis, J Neurosci Methods, 96 (2000), 147-152 [52] A. Bernhardt, A. Lode, S. Boxberger, W. Pompe and M. Gelinsky, Mineralised collagen —an artificial, extracellular bone matrix-improves osteogenic differentiation of bone marrow stromal cells, J Mater Sci Mater Med, 19 (2008), 269-275 [53] A. Grada, J. Mervis and V. Falanga, Research Techniques Made Simple: Animal Models of Wound Healing, J Investig Dermatol, 138 (2018), 2095-2105.e1

Quantitative and reproducible murine model of excisional wound healing, Wound Repair Regen, 12 (2004), 485-492

[55] J. P. E. Junker, R. A. Kamel, E. J. Caterson and E. Eriksson, Clinical Impact Upon Wound Healing and Inflammation in Moist, Wet, and Dry Environments, Adv Wound Care, 2 (2013), 348-356

[56] M. J. Jackson, D. A. Jones and R. H. T. Edwards, Tissue zinc levels as an index of body zinc status, Clin Physiol, 2 (1982), 333-343 [57] G. F. Caetano, M. Fronza, M. N. Leite, A. Gomes and M. A. C. Frade, Comparison of collagen content in skin wounds evaluated by biochemical assay and by computer-aided histomorphometric analysis, Pharm Biol, 54 (2016), 2555-2559 
1 [58] A. B. Farris, C. D. Adams, N. Brousaides, P. A. Della Pelle, A. B. Collins, E. Moradi, R. 2 N. Smith, P. C. Grimm and R. B. Colvin, Morphometric and Visual Evaluation of Fibrosis in 3 Renal Biopsies, J Am Soc Nephrol, 22 (2011), 176-186

4 [59] W. A. Dorsett-Martin, A. B. Wysocki. Rat Models of Skin Wound Healing. In: Conn 5 P.M. (eds) Sourcebook of Models for Biomedical Research. Humana Press, (2008), 631-638 6 [60] C.D. Marshall, M. S Hu, T. Leavitt, L. A. Barnes, H. P. Lorenz and M. T. Longaker. 7 Cutaneous Scarring: Basic Science, Current Treatments, and Future Directions, Adv Wound 8 Care, 7 (2016), 29-45 